[This document contains the author's accepted manuscript. For the publisher's version, see the link in the header of this document.]

\title{
Bayesian and Belief-Functions Formulas for Auditor Independence Risk Assessment
}

\author{
By Rajendra P. Srivastava, Theodore J. Mock, and Jerry L. Turner \\ University of Kansas, University of California, Riverside and University of Maastricht, \\ and the University of Memphis
}

\author{
Paper citation: \\ Srivastava, Rajendra. (2009) Bayesian and Belief Functions Formulas for Auditor Independence \\ Risk Assessment. International Journal of Auditing, 3, 163-183.
}

\section{Keywords:}

Auditor independence, audit risk, safeguards, threats, probability theory, belief functions

\begin{abstract}
:
This paper illustrates two formulas for assessing independence risk based on the Bayesian and belief-functions frameworks. These formulas can be used to assess the role of threats to auditor independence as well as the role of threat-mitigating safeguards. Also, these formulas provide a basis for evaluation of an audit firm's independence risk and a framework to educate stakeholders about the threats faced by the audit firm and the role of effective safeguards in mitigating these risks. The formulas also provide a means for regulators and lawmakers to evaluate whether they have effective safeguards in place given the existence of threats and for auditors to signal to various stakeholders that they have identified significant threats and have effective safeguards in place. To show the potential usefulness of these analytical models, several illustrations addressing increased transparency and the potential impact of regulations are presented.
\end{abstract}




\title{
Bayesian and Belief-Functions Formulas for Auditor Independence Risk Assessment
}

\author{
Rajendra P. Srivastava, ${ }^{1}$ Theodore J. Mock ${ }^{2}$ and \\ Jerry L. Turner ${ }^{3}$ \\ ${ }^{1}$ University of Kansas \\ ${ }^{2}$ University of California, Riverside and University Maastricht \\ ${ }^{3}$ The University of Memphis
}

This paper illustrates two formulas for assessing independence risk based on the Bayesian and belief-functions frameworks. These formulas can be used to assess the role of threats to auditor independence as well as the role of threat-mitigating safeguards. Also, these formulas provide a basis for evaluation of an audit firm's independence risk and a framework to educate stakeholders about the threats faced by the audit firm and the role of effective safeguards in mitigating these risks. The formulas also provide a means for regulators and lawmakers to evaluate whether they have effective safeguards in place given the existence of threats and for auditors to signal to various stakeholders that they have identified significant threats and have effective safeguards in place. To show the potential usefulness of these analytical models, several illustrations addressing increased transparency and the potential impact of regulations are presented.

Key words: Auditor independence, audit risk, safeguards, threats, probability theory, belief functions

\section{SUMMARY}

The enactment of significant new regulations and laws such as the Sarbanes-Oxley Act of 2002 (SOX), and the severe penalties recently being imposed on audit firms highlight the importance of auditor independence to the profession. Auditor independence, both in fact and in appearance, is vital to the value of attest services and thus to the

Correspondence to: Rajendra P. Srivastava, University of Kansas, KU School of Business, 1300 Sunnyside Avenue, Lawrence, KS 66045, USA. Email: rsrivastava@ku.edu viability of the auditing profession. Independent auditors have an important public trust in that investors must be able to rely on issuers' financial statements. If investors do not believe that an auditor is independent of an audit client, little confidence will be derived from the auditor's opinion and the investor will be less likely to invest in that company's securities (SEC, 2001). In testimony before the US Securities and Exchange Commission (SEC), Ralph Whitworth, Managing Member, Relational Investors LLC, argued that '[A]uditor independence goes to the very essence

ISSN 1090-6738

(C) 2009 The Author(s)

Journal compilation (C) 2009 Blackwell Publishing Ltd, 9600 Garsington Rd, Oxford OX4 2DQ,

UK and Main St., Malden, MA 01248, USA. 
of our capital markets, and it's linked inextricably to the efficiencies of our capitalist system' (SEC, 2000).

Given that auditor independence is critical, there is a need for a means to measure and control the risk that independence may be impaired. That risk, defined as independence risk, is the risk that threats to auditor independence, to the extent that they are not mitigated by safeguards, compromise or can reasonably be expected to compromise, an auditor's ability to make unbiased audit decisions about the financial statements of a specific attest client (ISB, 2000).

To date, an analytical formula for auditor independence risk that facilitates assessment of that risk has not existed. The objective of this paper is to present and illustrate analytical formulas of independence risk that are based on an existing general framework. As these formulas are based on two analytical approaches, Bayesian inference and Dempster-Shafer theory of belief functions (Shafer, 1976), they provide a level of rigor to the assessment of independence risk not previously available. Importantly, we include in each formulation the three components of an 'independence risk triangle' similar in form to that implied for fraud in SAS No. 99, Consideration of Fraud in a Financial Statement Audit (AICPA, 2002).

The basis for model development is the International Federation of Accountants (IFAC) framework. This framework is intended to assist the auditor in identifying threats to independence, to evaluate the significance of those threats, and to identify and apply effective safeguards to eliminate the threats or reduce them to an acceptable level (IFAC, 2008). Our model expands this framework by adding factors related to opportunities for the auditor to act in a manner biased toward the audit client and factors related to the possibility of the auditor possessing an inappropriate attitude toward compliance with ethics rules related to independence.

The AICPA Code of Professional Conduct indicates that independence is evaluated with respect to a particular attest client (AICPA, 2005). Accordingly, our model measures the risk of impaired independence at the engagement level. However, individual measures of independence risk can be aggregated to determine an overall level of independence for an entire audit firm and even for the profession as a whole. This flexibility provides a basis for regulators to evaluate whether they have effective safeguards in place, for audit firm self-assessments of independence risk, and as a basis to educate audit staff about the threats faced by the firm and by individual auditors. The model also can provide a means for auditors to signal to financial markets that they have identified significant threats and have effective safeguards in place.

While the IFAC framework identifies threats that may affect independence risk, it does not offer a methodology for combining judgments about the level of threats identified or the effectiveness of safeguards related to those threats. An initial attempt at providing such a methodology was presented in previous work by Turner et al. (2002). However, the Turner et al. study uses a simplistic version of the model presented in this paper and does not derive an analytical formula. The prior model also does not explicitly consider the possibility of interactions among the key variables that affect independence, nor does it explicitly consider the effect of regulation or of transparency on the perceived risk of impaired independence.

The remainder of this paper begins with a review of relevant prior research on auditor independence. We then develop our overall model that identifies the threats and safeguards associated with auditor attitude, incentives for bias, opportunities for bias to occur, and interrelationships between those three factors. Next, we develop two formulas for independence risk assessment, one based on Bayesian theory and a second based on the Dempster-Shafer theory of belief functions. To demonstrate the use of each formula, we provide illustrations of the risk assessment process considering several different scenarios. In the final section, we provide a summary and provide recommendations for future research.

\section{PRIOR RESEARCH}

Several branches of research examine aspects of auditor independence. One substantial branch investigates auditor self-interest threats to independence resulting from the provision of non-audit services. Some studies, such as Frankel et al. (2002), find evidence that the provision of non-audit services is correlated with evidence of more aggressive earnings management in audited financial statements. Other studies, such as DeFond et al. (2002), Jenkins \& Krawczyk (2002), Ashbaugh et al. (2003), Chung \& Kallapur (2003), and Brandon et al. (2004), fail to find such correlations. Reynolds et al. (2004) find evidence 
Srivastava, Rajendra. (2009) Bayesian and Belief Functions Formulas for Auditor Independence Risk Assessment. International Journal of Auditing, 3, 163-183. Publisher's Official Version: <http://onlinelibrary.wiley.com/journal/10.1111/\%28ISSN\%291099-1123>. Open Access Version: <http://kuscholarworks.ku.edu/dspace/>.

supporting Frankel et al. (2002), but determine that the correlations are situational. The perception of a self-interest threat, however, remains for regulators to the extent that SOX prohibits auditors from providing certain non-audit services to publicly-traded audit clients.

Another branch of research (e.g. Antle et al., 1997; Burke, 1997; Shafer et al., 1999) investigates the impact of intrinsic and extrinsic factors affecting the willingness of an auditor to comply with or violate independence guidelines. While these studies generally reflect a positive perception of auditor integrity, outside observers may perceive that self-interest or other threats may cause an auditor to ignore potential punishments and allow independence to be impaired.

The environment in which auditors function also has been studied. Ryan et al. (2001) examine SEC rules on independence, while Glazer \& Jaenicke (2002) provide details of how the SEC elected to continue with rules-based independence requirements rather than accepting a principlesbased code. Shafer et al. (1999) investigate auditors' perceptions of the effectiveness of formal sanctions as incentives for maintaining independence. The results of their experimental study indicate that litigation risk and peer-review risk were perceived as significant deterrents to aggressive reporting decisions, but the risk of disciplinary action by professional organizations was not. Hodge (2003) investigates investors' perceptions of earnings quality, auditor independence, and the usefulness of audited financial information. He finds that perceived earnings quality for all publicly-traded firms has declined over time, as has perceived auditor independence and the perceived reliability of audited financial information.

Several studies have proposed new approaches to defining auditor independence. Johnstone et al. (2001), for example, present a framework reflecting the combined effects on independence risk of direct incentives, indirect incentives, and judgment-based decisions involving difficult accounting issues, materiality, and audit conduct. They identify a variety of factors that may mitigate independence risk, including corporate governance mechanisms, regulatory oversight, auditing firm policies, auditing firm culture, and individual auditor characteristics. Taylor et al. (2003) also propose a general framework focusing on auditor reliability rather than solely on auditor independence. Their framework includes three foundational elements to control subjectivity in auditors' judgments and decisions: independence, integrity, and expertise. Each element is a necessary but not sufficient condition for maximizing objectivity, but objectivity, in turn, is a necessary and sufficient condition for achieving and maintaining reliability in fact and appearance. One basis for the Taylor et al. framework is the argument that because auditors are paid by the audit clients, an auditor always has the potential not to be independent. The Taylor et al. framework is intended to allow less than perfect independence as long as auditor reliability is sufficient. Like Johnstone et al. (2001), Taylor et al. (2003) do not attempt to operationalize their framework.

Turner et al. (2002) present a formal model of independence risk that assesses the impact of three variables - Incentives, Opportunity and Integrity and various safeguards on independence risk. The key element of their model is an assessment of the belief that independence is maintained, given beliefs about the three variables affecting this belief and evidence concerning various factors mitigating this belief. The assessment of independence risk is operationalized through an evidential network and risk assessments based on the theory of belief functions (Shafer, 1976). Although a first step at formally modeling independence risk, their model is quite simplistic as it does not model possible interactions between the variables, nor does it attempt to explicitly assess either the impact of additional regulations or safeguards or the impact of greater transparency with respect to audit firm policies and procedures that attempt to limit independence risk. This paper attempts to remedy these limitations. Importantly, it extends the previous model significantly by also developing a Bayesian model of the auditor independence risk with the same level of conceptual complexities. Some will find a Bayesian formulation to be more familiar and to be easier to use to augment the risk assessment tools they currently utilize.

\section{A FRAMEWORK FOR ASSESSING INDEPENDENCE RISK}

In this section we develop a general framework for assessing auditor independence risk. The framework is then used as a basis for development of analytical formulas for the assessment of auditor independence risk.

In the United States, the organizations responsible for establishing guidelines for auditor independence - the American Institute of Certified 
Public Accountants (AICPA), the SEC, the Public Company Accounting Oversight Board (PCAOB) and the Government Accountability Office (GAO) each have decided that a general framework based on threats and safeguards may not be effective and, instead, rely on approaches that list rules where specific actions either are required or are prohibited (see, e.g., Ryan et al., 2001; Bloom \& Myring, 2002; Glazer \& Jaenicke, 2002).

In 2000, the Independence Standards Board produced an exposure draft, Statement of Independence Concepts: A Conceptual Framework for Auditor Independence (ISB, 2000), proposing a framework and model for independence risk consistent with current international standards. That framework and model were rejected by the SEC in favor of continuing the existing rules-based approach (Glazer \& Jaenicke, 2002).

The existing rules-based approach also is evident in the provisions of SOX, which includes both specific prohibitions, such as the provision of some, but not all, non-audit services, and specific requirements, such as audit partner rotation. Knowing what the rules are may not be satisfactory, as Arthur Andersen LLP found out, when a firm is (or regulators are) attempting to monitor independence risk. And, because rules tend to be added on an 'as-needed' basis in response to specific circumstances, development of a parsimonious model for independence risk that is rules-based is problematic.

Alternatively, much of the auditing community outside the United States has elected to use a threat/safeguard, principles-based framework for defining and assessing auditor independence. The threat/safeguard approach adopted by the IFAC has been accepted in many countries, including Australia, Canada and Great Britain and is detailed in the Code of Ethics for Professional Accountants included in the 2008 Handbook of Auditing, Assurance, and Ethics Pronouncements (IFAC, 2008). Identified in the framework are five categories of threats: self-interest threats, self-review threats, advocacy threats, familiarity threats, and

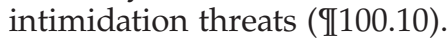

When significant threats are identified, the framework indicates that effective safeguards should be identified and applied to eliminate the threats or reduce them to an acceptable level. Framework safeguards fall into two broad categories (\$100.11): safeguards created by the profession, legislation, or regulation, and safeguards within the work environment. Each of these safeguard categories includes numerous ways of reducing or eliminating threats to auditor independence.

As a basis for a formal model of auditor independence risk, we posit that the issuance of a biased auditor's report is analogous to the creation of fraudulent financial statements by a company's management. That is, by intentionally issuing an inappropriate opinion, the auditor is falsely representing that he or she believes that the accompanying financial statements are presented fairly in accordance with generally accepted accounting principles. Such a misrepresentation potentially meets the legal requirements for fraud that there is an intentional false representation of a material fact and there may be justifiable reliance and possible loss or injury based on the false representation.

As discussed in SAS No. 99, three conditions generally are present when fraud exists: incentives/pressures, attitudes/rationalizations, and opportunities (II33). If auditor bias can be considered a form of fraud, the same three conditions should be present if an auditor intentionally issues an inappropriate audit opinion. For brevity, these components are identified hereafter as Incentive, Attitude, and Opportunity.

Turner et al. (2002) develop a model of independence risk integrating the three components identified in SAS No. 99. We use the same three components, creating an 'independence triangle' similar to the 'fraud triangle' envisioned in SAS No. 99. We then extend the Turner et al. model by integrating the threats and safeguards included in the 2008 Code of Ethics for Professional Accountants (IFAC, 2008). We elect to use a threats and safeguards approach as this allows development of a more general model in which independence risk can be evaluated either in a principles-based regulatory environment or a more situational, rules-based environment. This approach also allows inclusion of additional threats and safeguards not identified either in the principles-based international standards or the rules-based US standards. Importantly, we enhance the model by adding three interrelationships, one between Incentive and Attitude, a second relationship between Attitude and Opportunity, and a third between Incentive and Opportunity. The complete model is shown in Figure 1.

While no empirical data identifying which threat categories are related to a specific independence triangle component currently exists, we present 
Srivastava, Rajendra. (2009) Bayesian and Belief Functions Formulas for Auditor Independence Risk Assessment. International Journal of Auditing, 3, 163-183. Publisher's Official Version: <http://onlinelibrary.wiley.com/journal/10.1111/\%28ISSN\%291099-1123>. Open Access Version: <http://kuscholarworks.ku.edu/dspace/>.

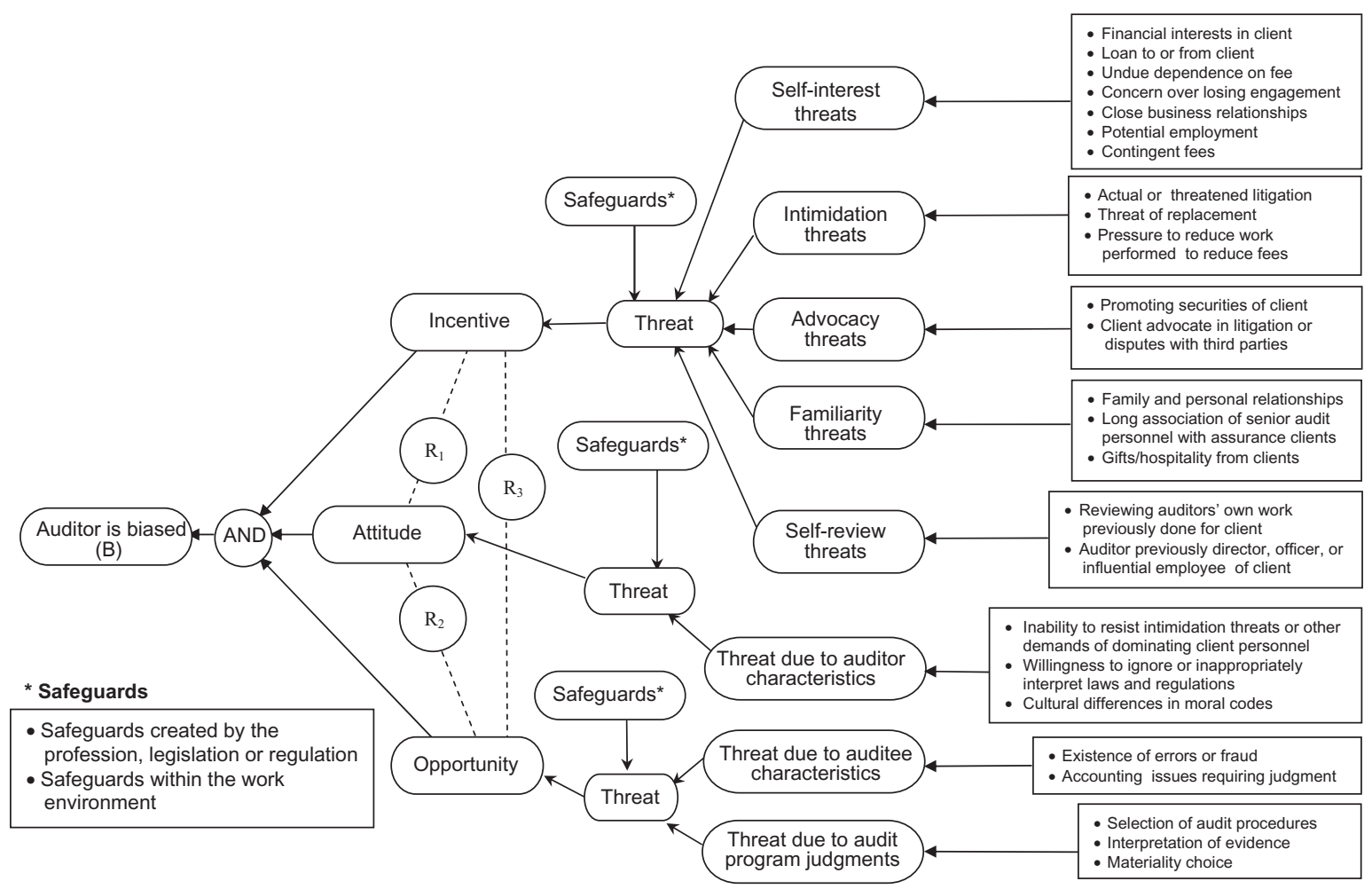

Figure 1: Model of independence risk (risk that the auditor is biased) with examples.

relationships that appear logical. It should be noted that categories for threats are general in nature and may not be mutually exclusive. For example, one type of threat might logically be assigned to more than one general category. The threats identified are for illustrative purposes only; however, we believe that such classification issues or possible interrelationships between threat categories do not affect the general structure of our model.

\section{Incentives}

Five categories of threats relate to Incentives: self-interest threats, self-review threats, advocacy threats, familiarity threats, and intimidation threats. Examples of self-interest threats include having a financial interest in a client, undue dependence on fees from a client, and potential employment with a client (IFAC, 2008, I200.4). Circumstances that may create self-review threats include having prepared the original data used to generate records that are the subject-matter of the engagement, reporting on the operation of financial systems after being involved in their design or implementation, and a member of the assurance team being, or having recently been, a director or officer of the client (IFAC, 2008, I200.5). Advocacy threats include acting as an advocate on behalf of an assurance client in litigation or disputes with third parties, and promoting ownership or other interests in an entity when that entity is a financial statement audit client (IFAC, 2008, II200.6). Circumstances that may create familiarity threats include a member of the engagement team having a close or immediate family relationship with a director or officer of the client, accepting gifts or preferential treatment from a client, unless the value is clearly insignificant, and long association of senior personnel with the assurance client (IFAC, 2008, I200.7). Intimidation threats include being threatened with dismissal or replacement, being threatened with litigation, and being pressured to reduce inappropriately the extent of work performed in order to reduce fees (IFAC, 2008, I[200.8). Each of these threats potentially creates an incentive for the auditor to provide 
Srivastava, Rajendra. (2009) Bayesian and Belief Functions Formulas for Auditor Independence Risk Assessment. International Journal of Auditing, 3, 163-183. Publisher's Official Version: <http://onlinelibrary.wiley.com/journal/10.1111/\%28ISSN\%291099-1123>. Open Access Version: <http://kuscholarworks.ku.edu/dspace/>.

an auditor's report containing an inappropriate opinion.

\section{Attitude/rationalization (integrity)}

The Code of Ethics for Professional Accountants notes that a distinguishing mark of the auditing profession is its acceptance of the responsibility to act in the public interest and not exclusively to satisfy the needs of an individual client or employer (IFAC, 2008, I100.1). In acting in the public interest, i.e., being independent, a professional accountant should observe and comply with five fundamental principles of professional ethics: integrity, objectivity, professional competence and due care, confidentiality, and professional behavior (IFAC, 2008, I100.4). Burke (1997) notes that there are both positive and negative intrinsic and extrinsic motivators that affect an auditor's desire and effort to maintain independence. Auditor interviews conducted by Burke indicate that intrinsic motivators are central to the auditor's commitment to maintain an objective and independent approach when working with audit clients. Burke also notes that while the potential for positive rewards engenders a strong sense of commitment to maintaining independence, potential punishments associated with not maintaining independence ensure a high level of compliance with the profession's rules and the firm's policies and procedures established to promote auditor independence.

\section{Auditor characteristics and attitude toward independence}

Even though both intrinsic and extrinsic motivators toward independence may exist, the attitude of an auditor still may threaten independence. Often, management personnel of audit clients have been successful at least in part due to the ability to dominate others. If the personality of the auditor is not sufficiently strong, demands by dominating audit client personnel may result in the auditor allowing inappropriate information to be included in or appropriate information excluded from financial statements.

Other characteristics of the auditor also may result in a threat to Attitude. While the audit profession excludes known criminals, an individual with weak moral character still may become an auditor. Such individuals may have a greater propensity to ignore or inappropriately interpret laws, regulations or professional standards and thus allow his or her independence to become impaired.

Many accounting ethics studies use Kohlberg's theory of ethical development (Kohlberg, 1971), which posits that individuals who have achieved a higher level of ethical development can be expected to behave in a more ethical manner. Rest's Defining Issues Test (DIT) (Rest, 1986a,b) has been the primary tool for measuring ethical development under Kohlberg's theory with a higher level of development indicated by a higher $p$-score. In the United States, it has been found that $p$-scores of accountants tend to decrease as rank increases (that is, partners, on average, have lower $p$-scores than do managers and seniors) (Ponemon, 1992; Shaub, 1994). Ethical development has also been linked to auditor sensitivity to management competence and integrity (Ponemon, 1993), auditor resistance to management pressure to misstate financial statement numbers (Tsui \& Gul, 1995), whistle-blowing attributions (Ponemon, 1990), auditor underreporting of time (Ponemon, 1992), auditor objectivity (Ponemon, 1995), and auditor independence judgments (Ponemon, 1990).

\section{Opportunity}

Even if an auditor is presented with a desirable incentive and is inclined to seek that incentive, an opportunity for auditor bias must exist. Opportunities may be available through choice of audit procedures to perform, interpretation of audit evidence, decisions regarding appropriate application of GAAP, and the choice of reporting materiality and implementation of that choice in deciding to waive recording of misstatements. Other opportunities such as the existence of known or likely errors, identified earnings manipulation and fraud also may exist.

\section{Safeguards}

When significant threats are identified, effective safeguards should be identified and applied with the nature of the safeguards depending on the circumstances. Consideration should always be given to what a reasonable and informed third party, having knowledge of all relevant information, including safeguards applied, would reasonably conclude to be unacceptable. The consideration will be affected by matters such as 
Srivastava, Rajendra. (2009) Bayesian and Belief Functions Formulas for Auditor Independence Risk Assessment. International Journal of Auditing, 3, 163-183. Publisher's Official Version: <http://onlinelibrary.wiley.com/journal/10.1111/\%28ISSN\%291099-1123>. Open Access Version: <http://kuscholarworks.ku.edu/dspace/>.

the significance of the threat, the nature of the attest engagement, the intended users of the auditor's report, and the structure of the firm (IFAC, 2008, I200.11). The two categories of safeguards are safeguards created by the profession, legislation or regulation, and safeguards within the work environment comprised of firm-wide safeguards and engagement-specific safeguards. Examples of firm-wide safeguards include such actions as policies and procedures to implement and monitor quality control of engagements, policies and procedures to enable identification of interests or relationships between the firm or members of engagement teams and clients, and policies and procedures to monitor and manage the reliance on revenue received from a single client. Engagement-specific safeguards may include involving an additional professional accountant to review the work done or otherwise advise as necessary and rotating senior assurance team personnel. Other examples of work environment safeguards are identified in the Code of Ethics for Professional Accountants (IFAC, 2008, I200.12, I200.13).

\section{Interrelationships}

A determination of an actual impairment of independence implies that all three main components of the independence risk triangle are present. However, a perception of impaired independence, for example lack of public confidence, can result from observations about only one or two of the three components while the other component(s) remain unobserved. This is recognized in SAS No. 1, which states, 'Public confidence would be impaired by evidence that independence was actually lacking, and it might also be impaired by the existence of circumstances which reasonable people might believe likely to influence independence' (AICPA, 1972, AU 220.03).

In recognizing the importance of perception, the SEC states, 'Because objectivity rarely can be observed directly, investor confidence in auditor independence rests in large measure on investor perception' (SEC, 2001, II III-A). The SEC also notes:

It is therefore not enough that financial statements be accurate; the public must also perceive them as being accurate. Public faith in the reliability of a corporation's financial statements depends upon the public perception of the outside auditor as an independent professional.... If investors were to view the auditor as an advocate for the corporate client, the value of the audit function itself might well be lost (SEC, 2001, II III-A).

We model perception of independence impairment by including three interrelationships between threat components of the independence risk triangle. These interrelationships allow assessments about any threat to propagate to each of the other threats without actual evidence about the other threats being necessary. In Figure 1, the three main categories of independence risk factors are connected by three relationships - one between 'Incentive' and 'Attitude', depicted by $\mathrm{R}_{1}$, a second between 'Attitude' and 'Opportunity', depicted by $\mathrm{R}_{2}$, and a third between 'Incentive' and 'Opportunity', depicted by $\mathrm{R}_{3}$.

Each of these relationships is bidirectional in its influence. For example, in the case of $R_{1}$, if there is evidence that the auditor has an Incentive to allow his or her judgment to be biased, then this relationship implies that the auditor's Attitude may rationalize the impairment of independence. Similarly, if there is evidence that the auditor has an inappropriate Attitude, this relationship implies that the auditor may identify or create an Incentive to his or her benefit. This relationship also implies that if the auditor does not have an inappropriate Attitude, the effect of Incentives for bias is negated or if there is no Incentive, the auditor would behave without bias. These relationships are modeled in the respective frameworks (Bayesian and belief-function frameworks) discussed below.

To derive the formulas for assessing the auditor independence risk under the two frameworks, we first simplify the general framework in Figure 1 into the evidential diagram shown in Figure 2. An evidential diagram, in general, is a schematic representation of the variables involved in a problem domain with their interrelationships, and the corresponding evidence that provides knowledge about the states or values of the variables (see, e.g., Srivastava \& Mock, 2000; and Sun et al., 2006). Usually such knowledge is only partial, that is the knowledge contains uncertainty, and thus one needs a language for managing uncertainty to map this knowledge. Shafer \& Tversky (1985) argue that choosing a framework for managing uncertainty is like choosing a 'formal language' or 'semantic'. The choice of a framework depends on the nature of uncertainty involved 


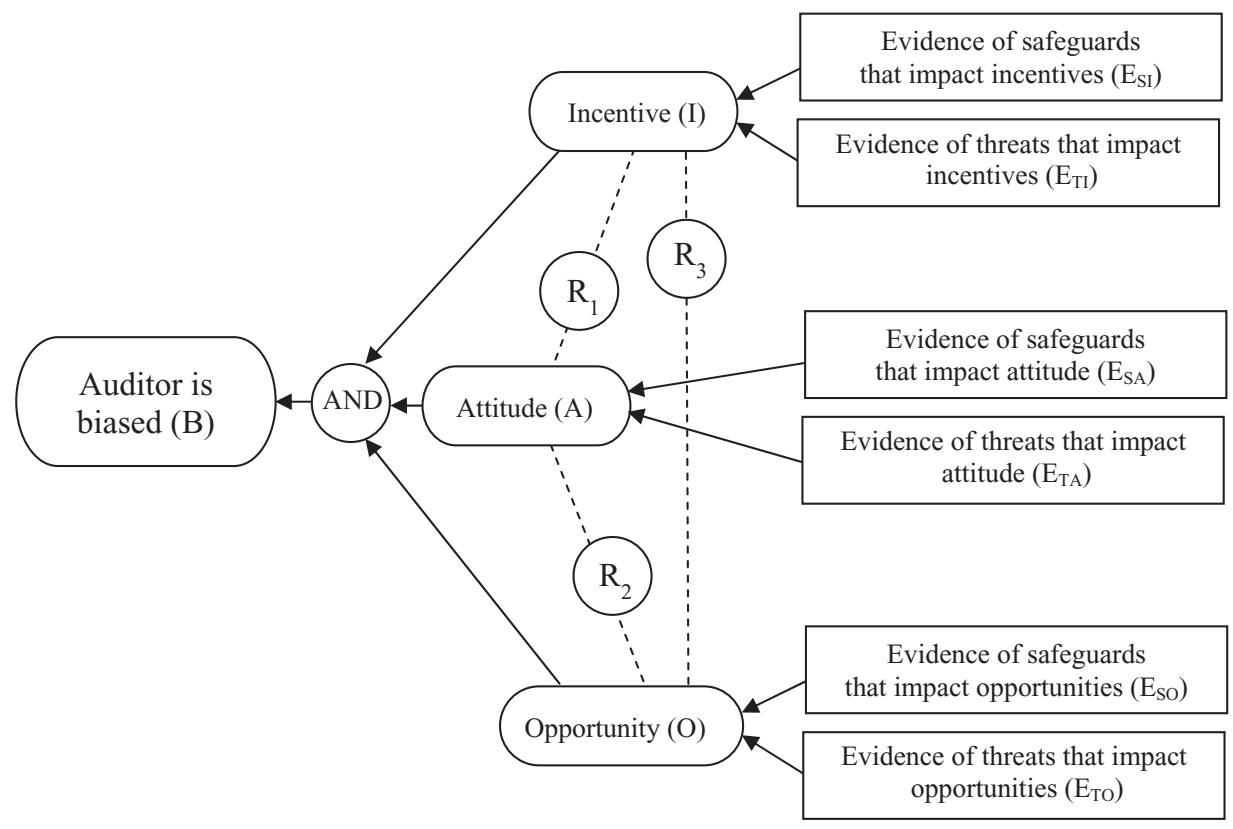

Figure 2: Evidential diagram for independence risk (i.e. state ' $B$ ', auditor is biased).

in the decision problem. In the present discussion we use two appropriate frameworks: the Bayesian framework and the belief-function framework. The Bayesian framework is the basis for most studies of decision-making under uncertainty. However, there exists a significant amount of research in decision-making using belief functions (e.g., Jaffray, 1989, 1994; Yager, 1990; Nguyen \& Walker, 1994). Although the belief-function (BF) framework has had limited application in auditing and accounting (Srivastava \& Mock, 2000; Sun et al., 2006), its use in other disciplines is growing, especially in assessing risks (see, e.g., Chen et al., 1992; McBurney \& Parsons, 2002; Démotier et al., 2003).

Figure 2 represents a simplified evidential diagram of Figure 1. The rounded boxes represent variables that take on two states or values such as whether or not the variable 'Incentives (I)' is present. The rectangular boxes represent items of evidence pertaining to the variables to which they are connected, and the circles represent relationships among the linked variables. To simplify the conceptual framework in Figure 1, we combine all the information about threats related to a variable into one item of evidence and all information about safeguards pertaining to a variable in another item of evidence.
The main variable of interest is the variable or assertion that 'The auditor is biased (B)' or in other words, the auditor lacks independence. This variable has two states or values, 'yes, the auditor is biased and lacks independence' represented by the symbol ' $b$ ', and 'the auditor is not biased' represented by ' $\sim b^{\prime}$. Thus all variables are assumed to be binary. We use upper case letters to represent the names of the variables and lower case letters to represent their values. For example, I represents incentives, ' $i$ ' represents that the incentives are present and ' $\sim \mathrm{i}$ ' represents that the incentives are not present.

As discussed earlier, the variable $\mathrm{B}$ is related to the three variables I, A, and O through an 'AND' relationship. The 'AND' relationship means that the auditor is biased if and only if there is incentive for the auditor to be biased, the auditor has attitude to be biased, and there are opportunities to be biased. In mathematical terms, we can express the 'AND' relationship between ' $\mathrm{B}$ ' and ' $\mathrm{I}$ ', ' $\mathrm{A}$ ', and ' $\mathrm{O}$ ' as $\mathrm{b}=\mathrm{i} \wedge \mathrm{a} \wedge \mathrm{O}$, where the symbol $\wedge$ represents conjunction. ${ }^{1}$ Because of the interrelationships within an evidential diagram, one can infer knowledge about one variable from the knowledge of the other variables. For example, knowledge about the presence or absence of the three variables, I, A, and $\mathrm{O}$, tells us something about 
Srivastava, Rajendra. (2009) Bayesian and Belief Functions Formulas for Auditor Independence Risk Assessment. International Journal of Auditing, 3, 163-183. Publisher's Official Version: <http://onlinelibrary.wiley.com/journal/10.1111/\%28ISSN\%291099-1123>. Open Access Version: <http://kuscholarworks.ku.edu/dspace/>.

the presence or absence of the variable B. In our formulations, this knowledge is represented in terms of probabilities and conditional probabilities or likelihood ratios under the Bayesian framework and in terms of basic belief masses (m-values) under the belief-function framework.

\section{FORMULAS FOR INDEPENDENCE RISK ASSESSMENT}

In developing our independence risk model under the Bayesian framework, we use the definition of risk as the posterior probability that the auditor will be biased in his or her judgment given evidence that the auditor has incentives, has an attitude to compromise, and has opportunities to be biased. Under the belief-function framework, we use the notion of risk contained in the Dempster-Shafer theory of belief functions (BF) as proposed by Srivastava and Shafer (1992) in terms of plausibility of the auditor being biased. The BF notion of risk is useful in situations such as the evaluation of independence risk where the evaluation must be made with limited information and when use of a Bayesian approach may be problematic due to lack of information.

In situations of limited information, and thus significant uncertainly about the probability that independence may be impaired; the belief function definition of risk is used to define risk as the plausibility of impaired independence. From this perspective, both direct evidence that would allow the assessor to question independence and ambiguity as to whether independence may be impaired or not is assigned to independence risk. This operationalization provides a conservative assessment of the risk in the sense that the highest assessment of this risk is used given both the evidence and ambiguity that exists. A lower assessment of independence risk may not be in the best interest of a profession that is striving to enhance its image. ${ }^{2}$

\section{Independence risk assessment formula under the Bayesian framework}

In this section we present the auditor independence risk assessment formula which is based on the Bayesian framework and assessments of probability. To derive this formula, we must identify all the probability information relevant in the problem domain as depicted in Figure 2, combine this information, and determine the posterior probability that the auditor is biased (lacks independence). This represents the auditor independence risk. The derivation of the formula is detailed in Srivastava et al. (2009) and is based on an analytical approach presented in Shenoy \& Shafer (1990) where the probability information is expressed in terms of probability potentials. A list of symbols and their description is given in Table 1.

From Srivastava et al. (2009), the following posterior probability represents the formula for auditor independence risk in terms of prior odds, $\pi^{\prime}$ s, likelihood ratios, ${ }^{3} \lambda^{\prime}$ s, and the interrelationships among the three factors, $\rho^{\prime}$ s:

$$
\begin{aligned}
& \text { Auditor Independence Risk = AIR(Bayes) } \\
& \quad=\mathrm{P}\left(\mathrm{b} \mid \mathrm{E}_{\mathrm{TI}} \mathrm{E}_{\mathrm{SI}} \mathrm{E}_{\mathrm{TA}} \mathrm{E}_{\mathrm{SA}} \mathrm{E}_{\mathrm{TO}} \mathrm{E}_{\mathrm{SO}}\right) \\
& \quad=\rho_{1} \rho_{2} \rho_{3} \lambda_{\mathrm{I}} \lambda_{\mathrm{A}} \lambda_{\mathrm{O}} \pi_{\mathrm{I}} \pi_{\mathrm{A}} \pi_{\mathrm{O}} \pi_{\mathrm{B}} / \mathrm{D}
\end{aligned}
$$

where D's are defined as:

$$
\begin{aligned}
& \mathrm{D}=\mathrm{D} 1+\mathrm{D} 2+\mathrm{D} 3+\mathrm{D} 4+\mathrm{D} 5+\mathrm{D} 6+\mathrm{D} 7+\mathrm{D} 8, \\
& \mathrm{D} 1=\rho_{1} \rho_{2} \rho_{3} \lambda_{\mathrm{I}} \lambda_{\mathrm{A}} \lambda_{\mathrm{O}} \pi_{\mathrm{I}} \pi_{\mathrm{A}} \pi_{\mathrm{O}} \pi_{\mathrm{B}}, \\
& \mathrm{D} 2=\left(1-\rho_{1}\right) \rho_{2}\left(1-\rho_{3}\right) \lambda_{\mathrm{A}} \lambda_{\mathrm{O}} \pi_{\mathrm{A}} \pi_{\mathrm{O}}, \\
& \mathrm{D} 3=\left(1-\rho_{1}\right)\left(1-\rho_{2}\right) \rho_{3} \lambda_{\mathrm{I}} \lambda_{\mathrm{O}} \pi_{\mathrm{I}} \pi_{\mathrm{O}}, \\
& \mathrm{D} 4=\rho_{1}\left(1-\rho_{2}\right)\left(1-\rho_{3}\right) \lambda_{\mathrm{I}} \lambda_{\mathrm{A}} \pi_{\mathrm{I}} \pi_{\mathrm{A}}, \\
& \mathrm{D} 5=\rho_{1}\left(1-\rho_{2}\right)\left(1-\rho_{3}\right) \lambda_{\mathrm{O}} \pi_{\mathrm{O}} \\
& \mathrm{D} 6=\left(1-\rho_{1}\right) \rho_{2}\left(1-\rho_{3}\right) \lambda_{\mathrm{I}} \pi_{\mathrm{I}} \\
& \mathrm{D} 7=\left(1-\rho_{1}\right)\left(1-\rho_{2}\right) \rho_{3} \lambda_{\mathrm{A}} \pi_{\mathrm{A}}, \\
& \mathrm{D} 8=\rho_{1} \rho_{2} \rho_{3} .
\end{aligned}
$$

And the prior odds, $\pi^{\prime}$ s, are defined as:

$$
\begin{aligned}
& \pi_{\mathrm{I}}=\mathrm{P}(\mathrm{i}) / \mathrm{P}(\sim \mathrm{i}), \pi_{\mathrm{A}}=\mathrm{P}(\mathrm{a}) / \mathrm{P}(\sim \mathrm{a}), \\
& \pi_{\mathrm{O}}=\mathrm{P}(\mathrm{o}) / \mathrm{P}(\sim \mathrm{o}), \pi_{\mathrm{B}}=\mathrm{P}(\mathrm{b}) / \mathrm{P}(\sim \mathrm{b}) .
\end{aligned}
$$

Equation (1) provides the auditor independence risk formula under Bayesian theory. The numerator in Equation (1) determines the impact on $\mathrm{B}$ of all the evidence gathered related to $\mathrm{I}, \mathrm{A}$, and $\mathrm{O}$. The denominator D consists of eight terms (D1, D2,...D8) as a result of Bayes' rule of conditioning. Thus, there are eight possible situations when the auditor will be biased or not biased as determined by the presence or absence of variables $\mathrm{I}, \mathrm{A}$, and $\mathrm{O}$.

In general, the likelihood ratio, $\lambda_{x}$, say for a variable $X$, is defined in terms of the conditional probabilities as: $\quad \lambda_{x}=P(E \mid x) / P(E \mid \sim x)$, and indicates (measures) the strength of the evidence $\mathrm{E}$ in support of the variable X (Edwards, 1984). $\lambda_{x}=1$ implies that the evidence provides no information 
Srivastava, Rajendra. (2009) Bayesian and Belief Functions Formulas for Auditor Independence Risk Assessment. International

Journal of Auditing, 3, 163-183. Publisher's Official Version: <http://onlinelibrary.wiley.com/journal/10.1111/\%28ISSN\%291099-1123>. Open Access Version: <http://kuscholarworks.ku.edu/dspace/>.

\section{Table 1: List of symbols and their descriptions}

\begin{tabular}{|c|c|}
\hline Symbol & Description \\
\hline A & represents the variable 'Attitude'. \\
\hline B & represents the variable 'Risk of Impaired Independence', i.e., Bias against independence. \\
\hline & represents the variable 'Incentive'. \\
\hline $\mathrm{O}$ & represents the variable 'Opportunity'. \\
\hline $\mathrm{E}_{\mathrm{TI}}$ & represents the evidence that threats related to incentives (I) are present. \\
\hline $\mathrm{E}_{\mathrm{SI}}$ & represents the evidence that safeguards related to incentives (I) are present. \\
\hline $\mathrm{E}_{\mathrm{TA}}$ & represents the evidence that threats related to attitude (A) are present. \\
\hline $\mathrm{E}_{\mathrm{SA}}$ & represents the evidence that safeguards related to attitude (A) are present. \\
\hline $\mathrm{E}_{\mathrm{TO}}$ & represents the evidence that threats related to opportunities (I) are present. \\
\hline $\mathrm{E}_{\mathrm{SO}}$ & represents the evidence that safeguards related to opportunities $(\mathrm{O})$ are present. \\
\hline$\rho_{1}, \rho_{2}, \rho_{3}$, & $\begin{array}{l}\rho \text { determines the strength of the interrelationship between two variables under the Bayesian } \\
\text { framework. A value of } 1.0 \text { represents the highest strength and } 0.5 \text { represents no } \\
\text { interrelationship. } \rho_{1} \text { is for the relationship between I and A, } \rho_{2} \text { for the relationship between A } \\
\text { and } \mathrm{O} \text {, and } \rho_{3} \text { for the relationship between } \mathrm{O} \text { and I. }\end{array}$ \\
\hline$r_{1}, r_{2}, r_{3}$ & $\begin{array}{l}\mathrm{r} \text { determines the strength of the interrelationship between two variables under the } \\
\text { belief-function framework. A value of } 1.0 \text { represents the highest strength and } 0 \text { represents no } \\
\text { interrelationship. } \mathrm{r}_{1} \text { is for the relationship between } \mathrm{I} \text { and } \mathrm{A}, \mathrm{r}_{2} \text { for the relationship between } \mathrm{A} \\
\text { and } \mathrm{O} \text {, and } \mathrm{r}_{3} \text { for the relationship between } \mathrm{O} \text { and } \mathrm{I} \text {. }\end{array}$ \\
\hline$\lambda_{\mathrm{I}}, \lambda_{\mathrm{A}}, \lambda_{\mathrm{O}}$ & $\begin{array}{l}\lambda \text { is the likelihood ratio which represents the strength of evidence under the Bayesian } \\
\text { framework. It is defined as the ratio of two conditional probabilities. For example, } \\
\lambda_{\mathrm{I}},=\mathrm{P}(\mathrm{E} \mid \mathrm{i}) / \mathrm{P}(\mathrm{E} \mid \sim \mathrm{i}) \text {, where } \mathrm{E} \text { represent the evidence. }\end{array}$ \\
\hline $\mathrm{m}_{.}^{+}$ & The basic belief mass, i.e., m-value, in support of the variable denoted by the subscript. \\
\hline & The basic belief mass, i.e., $\mathrm{m}$-value, against the variable denoted by the subscript. \\
\hline $\mathrm{m}_{\ddot{\Theta}}^{\ddot{\theta}}$ & The basic belief mass, i.e., $\mathrm{m}$-value, representing unassigned beliefs or ambiguity. \\
\hline $\mathrm{Pl}(i)$ & Plausibility or risk that Incentives are present due to threat factors. \\
\hline $\mathrm{Pl}(a)$ & Plausibility or risk that Attitude to be biased is present due to threat factors. \\
\hline $\mathrm{Pl}(0)$ & Plausibility or risk that Opportunities are present due to threat factors. \\
\hline
\end{tabular}

about the presence or absence of the variable $X$. A positive value greater than $1\left(\infty>\lambda_{x}>1\right)$ implies that evidence supports that the variable $X$ is true, i.e., there is some reason to believe that $\mathrm{X}$ is true. $\mathrm{A}$ value of less than one $\left(1>\lambda_{x} \geq 0\right)$ implies that the evidence negates the variable. Theoretically, an infinitely large positive value of a likelihood ratio implies that the variable is true with probability 1.0. For example, $\lambda_{\mathrm{I}} \rightarrow \infty$ implies that we are certain the auditor has Incentive and a value of 0 , i.e., $\lambda_{\mathrm{I}}=0$, implies, with certainty, that the auditor has no Incentive.

The interrelationships, $\rho_{1}, \rho_{2}$, and $\rho_{3}$, determine the strength of the relationship among the three factors. A value of 1.0 represents the strongest relationship implying that if one variable is present then the other related variable is present also. A value of 0.5 represents no relationship between the variables. These relationships are symmetric and are defined as: $\rho_{1}=\mathrm{P}(\mathrm{a} \mid \mathrm{i})=\mathrm{P}(\sim \mathrm{a} \mid \sim \mathrm{i}), \rho_{2}=\mathrm{P}(\mathrm{o} \mid \mathrm{a})=$ $\mathrm{P}(\sim \mathrm{O} \mid \sim \mathrm{a})$, and $\rho_{3}=\mathrm{P}(\mathrm{i} \mid \mathrm{o})=\mathrm{P}(\sim \mathrm{i} \mid \sim \mathrm{O})$ (see Srivastava et al., 2009, for more details).

\section{Formulas for the belief and plausibility of the auditor being biased under belief functions}

In this section we present formulas for the evidential diagram depicted in Figure 2 based on the Dempster-Shafer theory of belief functions (Shafer, 1976) for assessing auditor independence risk and the belief that the auditor lacks independence (is biased). For comparison purposes, we use the same evidential diagram as was used in the Bayesian case.

To derive the auditor independence risk formula and the formula for the belief that the auditor is biased, we first determine the impacts of safeguard factors on threat factors and then the impact of threat factors on the corresponding variables I, A, and $\mathrm{O}$, in Figure 2, in terms of $\mathrm{m}$-values, i.e., in terms of basic belief masses. ${ }^{4}$ Next, we combine the three sets of m-values (one set for each variable) obtained in the above process taking into consideration the interrelationships among the 
Srivastava, Rajendra. (2009) Bayesian and Belief Functions Formulas for Auditor Independence Risk Assessment. International Journal of Auditing, 3, 163-183. Publisher's Official Version: <http://onlinelibrary.wiley.com/journal/10.1111/\%28ISSN\%291099-1123>. Open Access Version: <http://kuscholarworks.ku.edu/dspace/>.

factors, $\mathrm{R}_{1}, \mathrm{R}_{2}$, and $\mathrm{R}_{3}$, and the 'AND' relationship between $\mathrm{B}$ and the three variables, $\mathrm{I}, \mathrm{A}$, and $\mathrm{O}$. We then propagate the resulting $\mathrm{m}$-values to $\mathrm{B}$. The above process yields the desired formulas for the auditor independence risk and belief that the auditor is biased. The details of the derivation are presented in Srivastava et al. (2007).

The two most important functions that would be useful in assessing whether the auditor is biased or not are the overall belief, $\operatorname{Bel}(b)$, and overall plausibility, $\mathrm{Pl}(\mathrm{b})$, that the auditor is biased. The belief that the auditor is biased, $\operatorname{Bel}(\mathrm{b})$, measures the definite belief in ' $b$ ' based on all the observed evidence. The plausibility that the auditor is biased, $\mathrm{Pl}(\mathrm{b})$, the worst case scenario, is defined to be the sum of the definite belief in ' $b$ ' plus the ambiguity existing in any unevaluated evidence.

From Srivastava et al. (2007), we obtain the following expression for the belief and plausibility that the auditor is biased in terms of the strength of three interrelationships, $r_{1}, r_{2}$, and $r_{3}$, and the belief masses, $\mathrm{m}_{.}^{+}, \mathrm{m}^{-}$, and $\mathrm{m}_{.}^{\Theta}$, representing, respectively, the level of support in favor of the variable, against the variables, and the unassigned belief, for the three variables I, A, and $\mathrm{O}$, represented by the subscript:

$$
\begin{aligned}
\operatorname{Bel}(b)= & {\left[\mathrm{m}_{\mathrm{I}}^{+} \mathrm{m}_{\mathrm{A}}^{+} \mathrm{m}_{\mathrm{O}}^{+}+\left(\mathrm{r}_{1}+\mathrm{r}_{2}-\mathrm{r}_{1} \mathrm{r}_{2}\right) \mathrm{m}_{\mathrm{I}}^{+} \mathrm{m}_{\mathrm{A}}^{\Theta} \mathrm{m}_{\mathrm{O}}^{+}+\right.} \\
& \left(\mathrm{r}_{1}+\mathrm{r}_{3}-\mathrm{r}_{1} \mathrm{r}_{3}\right) \mathrm{m}_{\mathrm{I}}^{\Theta} \mathrm{m}_{\mathrm{A}}^{+} \mathrm{m}_{\mathrm{O}}^{+}+ \\
& \left(\mathrm{r}_{2}+\mathrm{r}_{3}-\mathrm{r}_{2} \mathrm{r}_{3}\right) \mathrm{m}_{\mathrm{I}}^{+} \mathrm{m}_{\mathrm{A}}^{+} \mathrm{m}_{\mathrm{O}}^{\Theta}+ \\
& \left(\mathrm{r}_{1} \mathrm{r}_{2}+\mathrm{r}_{2} \mathrm{r}_{3}+\mathrm{r}_{1} \mathrm{r}_{3}-2 \mathrm{r}_{1} \mathrm{r}_{2} \mathrm{r}_{3}\right)\left(\mathrm{m}_{\mathrm{I}}^{+} \mathrm{m}_{\mathrm{A}}^{\Theta} \mathrm{m}_{\mathrm{O}}^{+}+\right. \\
& \left.\left.\mathrm{m}_{\mathrm{I}}^{\Theta} \mathrm{m}_{\mathrm{A}}^{+} \mathrm{m}_{\mathrm{O}}^{\Theta}+\mathrm{m}_{\mathrm{I}}^{\Theta} \mathrm{m}_{\mathrm{A}}^{\Theta} \mathrm{m}_{\mathrm{O}}^{+}\right)\right] / \mathrm{K} \\
\operatorname{Pl}(\mathrm{b})= & \left(\mathrm{m}_{\mathrm{I}}^{+}+\mathrm{m}_{\mathrm{A}}^{\Theta}\right)\left(\mathrm{m}_{\mathrm{A}}^{+}+\mathrm{m}_{\mathrm{A}}^{\Theta}\right)\left(\mathrm{m}_{\mathrm{O}}^{+}+\mathrm{m}_{\mathrm{O}}^{\Theta}\right) / \mathrm{K}
\end{aligned}
$$

where $\mathrm{K}$ is defined as

$$
\begin{aligned}
& \mathrm{K}=1-\left[\mathrm{r}_{2}+\mathrm{r}_{1} \mathrm{r}_{3}\left(1-\mathrm{r}_{2}\right)\right] \mathrm{m}_{\mathrm{I}}^{\Theta}\left(\mathrm{m}_{\mathrm{A}}^{-} \mathrm{m}_{\mathrm{O}}^{+}+\mathrm{m}_{\mathrm{A}}^{+} \mathrm{m}_{\mathrm{O}}^{-}\right)- \\
& {\left[\mathrm{r}_{3}+\mathrm{r}_{1} \mathrm{r}_{2}\left(1-\mathrm{r}_{3}\right)\right] \mathrm{m}_{\mathrm{A}}^{\ominus}\left(\mathrm{m}_{\mathrm{I}}^{-} \mathrm{m}_{\mathrm{O}}^{+}+\mathrm{m}_{\mathrm{I}}^{+} \mathrm{m}_{\mathrm{O}}^{-}\right)-} \\
& {\left[\mathrm{r}_{1}+\mathrm{r}_{2} \mathrm{r}_{3}\left(1-\mathrm{r}_{1}\right)\right] \mathrm{m}_{\mathrm{O}}^{\ominus}\left(\mathrm{m}_{\mathrm{I}}^{-} \mathrm{m}_{\mathrm{A}}^{+}+\mathrm{m}_{\mathrm{I}}^{+} \mathrm{m}_{\mathrm{A}}^{-}\right)-} \\
&\left(\mathrm{r}_{1}+\mathrm{r}_{2}-\mathrm{r}_{1} \mathrm{r}_{2}\right)\left(\mathrm{m}_{\mathrm{I}}^{-} \mathrm{m}_{\mathrm{A}}^{+} \mathrm{m}_{\mathrm{O}}^{-}+\mathrm{m}_{\mathrm{I}}^{+} \mathrm{m}_{\mathrm{A}}^{-} \mathrm{m}_{\mathrm{O}}^{+}\right)- \\
&\left(\mathrm{r}_{2}+\mathrm{r}_{3}-\mathrm{r}_{2} \mathrm{r}_{3}\right)\left(\mathrm{m}_{\mathrm{I}}^{-} \mathrm{m}_{\mathrm{A}}^{-} \mathrm{m}_{\mathrm{O}}^{+}+\mathrm{m}_{\mathrm{I}}^{+} \mathrm{m}_{\mathrm{A}}^{+} \mathrm{m}_{\mathrm{O}}^{-}\right)- \\
&\left(\mathrm{r}_{1}+\mathrm{r}_{3}-\mathrm{r}_{1} \mathrm{r}_{3}\right)\left(\mathrm{m}_{\mathrm{I}}^{+} \mathrm{m}_{\mathrm{A}}^{-} \mathrm{m}_{\mathrm{O}}^{-}+\mathrm{m}_{\mathrm{I}}^{-} \mathrm{m}_{\mathrm{A}}^{+} \mathrm{m}_{\mathrm{O}}^{+}\right)
\end{aligned}
$$

The interrelationship ' $r$ ' determines the strength of the relationship between two variables being related under the belief-function framework. Similar to the definition of an interrelationship in a Bayesian framework, this relationship is symmetric and a value of 1.0 represents the strongest relationship. This implies that if one variable is true then the other also is true. A value of 0 for ' $r$ ' implies no relationship. The symbol $r_{1}$ represents the strength of the interrelationship between I and $\mathrm{A}, \mathrm{r}_{2}$ between $\mathrm{A}$ and $\mathrm{O}$, and $\mathrm{r}_{3}$ between $\mathrm{O}$ and $\mathrm{I}$.

Equation (5) is the desired auditor independence risk formula and can be simplified further by substituting $\left(\mathrm{m}_{\mathrm{I}}^{+}+\mathrm{m}_{\mathrm{I}}^{\ominus}\right)=\mathrm{Pl}(\mathrm{i}), \quad\left(\mathrm{m}_{\mathrm{A}}^{+}+\mathrm{m}_{\mathrm{A}}^{\Theta}\right)=\mathrm{Pl}(\mathrm{a})$, and $\left(\mathrm{m}_{\mathrm{O}}^{+}+\mathrm{m}_{\mathrm{O}}^{\ominus}\right)=\mathrm{Pl}(\mathrm{o})$, where $\mathrm{Pl}(\mathrm{i}), \mathrm{Pl}(\mathrm{a})$, and $\mathrm{Pl}(\mathrm{o})$ represent the plausibility that incentives, attitude and opportunities are present even after considering the effect of the corresponding safeguards. That is, these plausibilities represent the risk that the corresponding factors are present. Thus, from (5) we can rewrite the auditor independence risk in terms of the plausibility of the auditor being biased as AIR(DS):

$$
\mathrm{AIR}(\mathrm{DS})=\mathrm{Pl}(\mathrm{b})=\mathrm{Pl}(\mathrm{i}) \cdot \mathrm{Pl}(\mathrm{a}) \cdot \mathrm{Pl}(\mathrm{o}) / \mathrm{K}
$$

where $\mathrm{K}$ is defined in (6), which depends on the interrelationships among the three factors, I, A, and O.

Equation (7) is a general formula for independence risk measured in terms of plausibility based on Figure 2. Various special cases can be derived from this general model. Note that (7) is a multiplicative model consisting of the product of three plausibilities or risk measures. The first term $\mathrm{Pl}(\mathrm{i})$ determines the risk or plausibility that incentives for the auditor to be biased are present even after considering the effects of the related safeguards. Similarly, the other two terms, $\mathrm{Pl}(\mathrm{a})$ and $\mathrm{Pl}(\mathrm{o})$, respectively, determine the risk that an inappropriate attitude is present, and that opportunities are present even after considering the effects of the corresponding safeguards.

Equation (7) makes logical sense. Auditor independence risk will exist if the following risks exist at the same time: incentives are present, an inappropriate auditor attitude is present, and opportunities for the auditor to be biased are present.

\section{ILLUSTRATIONS AND ANALYSIS OF THE MODELS}

To demonstrate the use of each formula, we first consider the impact of interrelationships on the two formulations of independence risk. Next, we analyze the impact of transparency of actions the auditor may take to enforce independence and analyze the impact of regulations on independence risk assessments. For comparison purposes, we use the same inputs in both frameworks by converting 
Srivastava, Rajendra. (2009) Bayesian and Belief Functions Formulas for Auditor Independence Risk Assessment. International Journal of Auditing, 3, 163-183. Publisher's Official Version: <http://onlinelibrary.wiley.com/journal/10.1111/\%28ISSN\%291099-1123>. Open Access Version: <http://kuscholarworks.ku.edu/dspace/>.

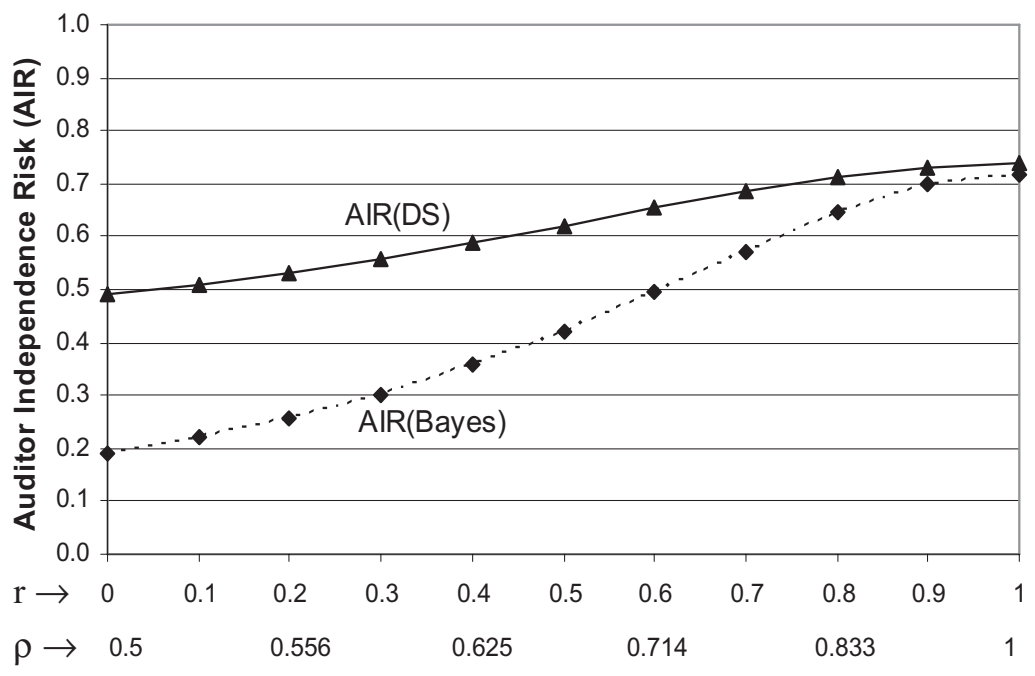

Strength of all three Interrelationships

Figure 3: Auditor independence risk $k^{\mathrm{a}}$ as a function of the strength of interrelationships ${ }^{\mathrm{b}}$.

${ }^{a}$ Defined as plausibility (AIR(DS)) and as probability (AIR(Bayes))

${ }^{\mathrm{b}}$ This graph assumes a high level of threat for incentives (I) and opportunities $(\mathrm{O})$ and a low level of safeguards for I and $\mathrm{O}$. These levels translate into the following set of $\mathrm{m}$-values: $\mathrm{m}_{\mathrm{I}}^{+}=0.56, \mathrm{~m}_{\mathrm{I}}^{-}=0.3, \mathrm{~m}_{\mathrm{O}}^{+}=0.56, \mathrm{~m}_{\mathrm{O}}^{-}=0.3$. No information is assumed to be available for attitude (A), $\mathrm{m}_{\mathrm{A}}^{-}=\mathrm{m}_{\mathrm{A}}^{-}=0$.

the belief inputs in DS theory to probabilities and conditional probabilities in the Bayesian framework using the Cobb \& Shenoy (2003) approach. $^{5}$

\section{Impact of the strength of interrelationships on auditor independence risk}

Figure 3 assumes the three interrelationships to be equal and plots the two models of auditor independence risk as a function of the strength of the interrelationships. As expected, independence risk in both cases increases with the increase in strength of the interrelationships. Given the same inputs for both models, the models show very similar trends and both are sensitive to assessments that would lead the auditor or any stakeholder to expect a stronger interrelationship between Incentive, Opportunity or Attitude. Also, independence risk defined under DS is more conservative (assessed higher) than the risk defined under Bayesian theory, especially at lower levels of interrelationships.

The difference between the independence risks under the two frameworks can be large, especially at a lower strength of interrelationships. This difference results from the way the two frameworks model ambiguity. In the probability framework, if it is not known whether a variable is true or false, a probability of 0.5 can be assigned to each state, representing lack of knowledge. However, under DS theory, zero belief mass is assigned to both states as there is no information to determine whether the variable is true or false. We have posited that in order for the auditor to be biased, all the three variables, I, A, and $\mathrm{O}$, must be present. Thus, under the Bayesian framework and under complete ignorance about the three factors, a lack of evidence implies that the auditor independence risk is 0.125 . In other words, there is only one possibility out of the eight potential possibilities for formula (1) that all the three factors are present.

Under DS theory, since we have zero belief mass that the three factors are either true or false, we obtain a zero belief that the auditor is biased or not biased. This results in a plausibility of 1 that the auditor could be biased, i.e., the auditor independence risk is 1.0 compared to 0.125 under the Bayesian framework. This implies that, given no evidence, DS theory would indicate that a high level of skepticism regarding auditor 
Srivastava, Rajendra. (2009) Bayesian and Belief Functions Formulas for Auditor Independence Risk Assessment. International Journal of Auditing, 3, 163-183. Publisher's Official Version: <http://onlinelibrary.wiley.com/journal/10.1111/\%28ISSN\%291099-1123>. Open Access Version: <http://kuscholarworks.ku.edu/dspace/>.

independence would be appropriate, whereas Bayesian theory would indicate a much lower level of concern.

In Figure 3 we assume there are safeguards related to incentives and opportunities effective at a moderate level. The effect of these safeguards result in a definite belief that the auditor is not biased, i.e., $\operatorname{Bel}(\sim b)>0$, whether there are interrelationships or not. Also, for this situation, the belief that the auditor is biased is zero, i.e., $\operatorname{Bel}(b)=0$, because not all the three factors are present for zero interrelationship since we have assumed a zero belief mass that the attitude is present. This results in a large ambiguity at zero interrelationships. However, as the interrelationships become stronger, the belief that the auditor is biased increases, as does the plausibility or risk that the auditor is biased and as a result reduces the ambiguity. This reduction in ambiguity with the increase in the strength of interrelationships brings the measure of independence risk closer to each other as seen in Figure 3. One can show that as the level of any threat increases, the assessed independence risk also increases in a similar fashion under both frameworks.

\section{The effects of improved transparency}

Section 202 of SOX mandates that audit committees be directly responsible for oversight of the engagement of the company's independent auditor and that the committee be informed about the services expected to be provided by the audit firm to understand whether the audit firm's independence will be impaired (OCA, 2007).

In this section, we demonstrate how the formulas can be used to assess the impact of transparency on AIR. Determining an appropriate amount of transparency seems to be a continuing concern of many participants in financial markets. To demonstrate differences in perceptions as they relate to evaluating the risk of impaired independence, we program the two models in (1) and (7) in a spreadsheet and then assign values to belief masses obtained from various items of evidence to calculate their effects on AIR.

As noted earlier, for an auditor to be assessed as being independent from an audit client there must be independence in appearance as well as in fact. Thus, independence risk is based to a large extent on stakeholder perceptions. Issues with respect to perception arise from two sources. First, an information asymmetry exists between the auditor and any external parties evaluating an auditor's independence. That is, complete evidence about threats and the effectiveness of safeguards is probably not available to every party wishing to evaluate AIR.

Second, while the auditor has a greater knowledge about existing threats and the effectiveness of safeguards, the auditor may evaluate threats and safeguards with a bias favorable toward him- or herself. Such asymmetry of information and potential bias creates two different perceptions of auditor independence the perception held by external observers having incomplete information on which to base a judgment and the perception held by the auditor who has more information, but may evaluate that information in a biased manner. The existence of information asymmetry has been confirmed by Maleszka \& Monroe (2004) who find that unsophisticated users, shareholders, sophisticated users and auditors have significantly different perceptions of auditor independence when presented with identical scenarios.

Of the three nodes - Opportunity, Attitude, and Incentive - external observers have only minimal information in regard to the first two. For example, in regard to Opportunity, auditors do not reveal publicly the nature, timing, or extent of audit procedures, nor do they reveal judgments made in regard to the outcomes of those procedures. Also, audit materiality is not disclosed nor is any information regarding waived audit adjustments. Thus, outside evaluators would be expected to assign a higher value of belief that threats related to Opportunity exist than would the auditor. Accordingly, external observers must rely on the effectiveness of safeguards such as those related to the auditor's compliance with generally accepted auditing standards. The auditor, of course, has complete information about these issues and may have much greater confidence that independence has not been impaired.

Information on which to evaluate the Attitude or integrity of the auditor in regard to potential bias also is very limited. In general, external observers must rely either on the auditor holding an appropriate certification and the certifying body having appropriate standards for obtaining and maintaining that certification or on regulatory bodies to enforce independence rules. Information about the ability of the auditor to resist intimidation, his or her willingness to interpret laws or principles, or cultural differences generally 
Srivastava, Rajendra. (2009) Bayesian and Belief Functions Formulas for Auditor Independence Risk Assessment. International Journal of Auditing, 3, 163-183. Publisher's Official Version: <http://onlinelibrary.wiley.com/journal/10.1111/\%28ISSN\%291099-1123>. Open Access Version: <http://kuscholarworks.ku.edu/dspace/>.

is unobservable externally. Of course, given a professional attitude on the part of the auditor and rational responses to intrinsic and extrinsic influences, the auditor likely will evaluate his or her own level of integrity at a high level.

To demonstrate how the AIR formulas can be used to assess the impact of transparency and associated perceptions, we use models (1) and (7) and assign values to belief masses obtained from various items of evidence. For analysis, we consider all three interrelationships: a relationship between Incentive and Attitude to compromise $\left(R_{1}\right)$, a relationship between Opportunity and Attitude to compromise $\left(R_{2}\right)$, and a relationship between Incentive and Opportunity $\left(R_{3}\right)$. These relationships are assumed to be at a medium level of strength of 0.6 , on a scale $0-1.0$, i.e., $\mathrm{r}_{1}=\mathrm{r}_{2}=\mathrm{r}_{3}=0.6$ in DS theory and $\rho_{1}=\rho_{2}=\rho_{3}=0.714$ under Bayesian theory (see endnote 5 for this conversion).

The first panel in Figure 4 shows the assessed independence risk based on the DS framework and
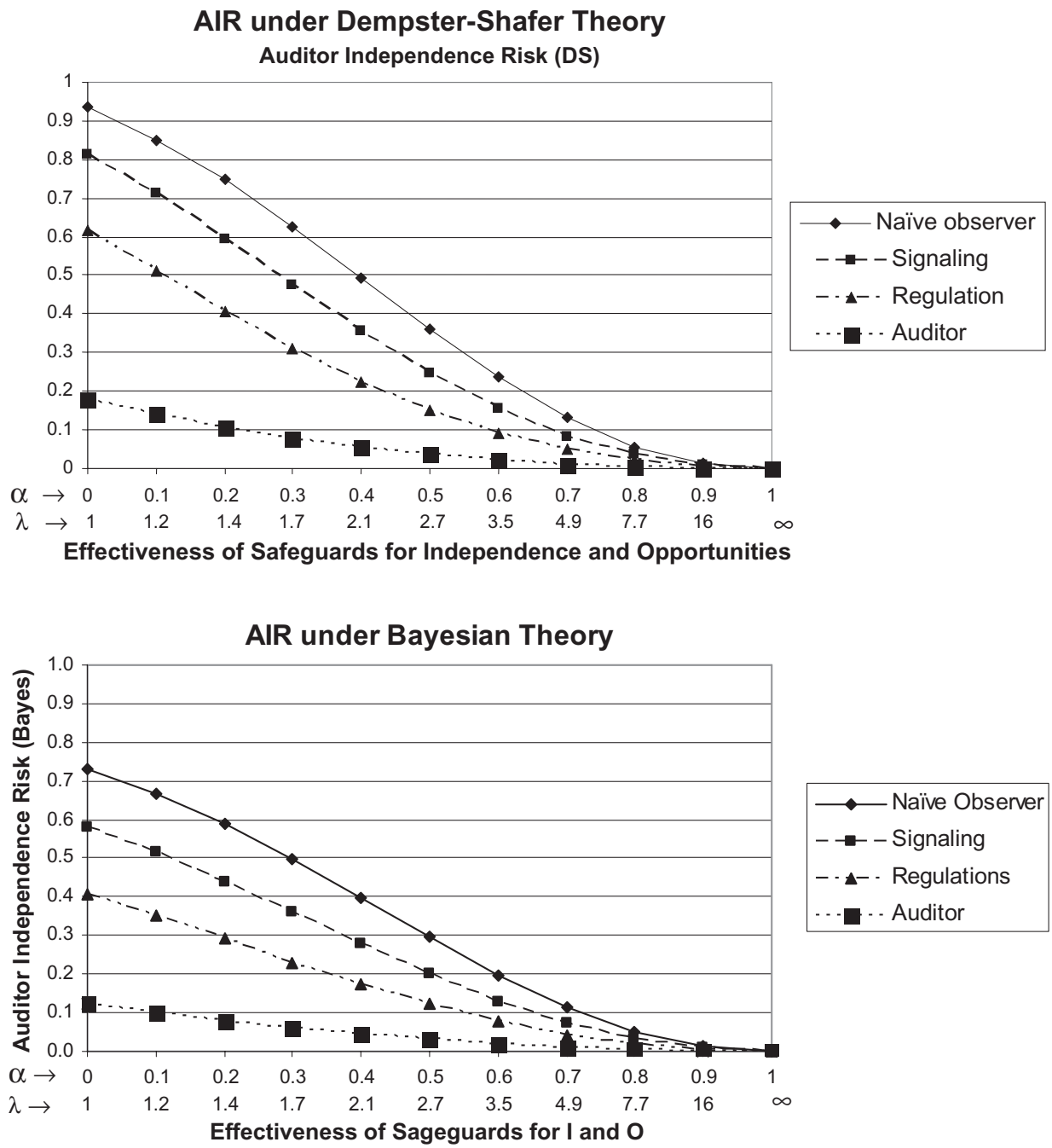

Figure 4: Auditor independence risk as a function of perceived effectiveness of safeguards against threats related to incentives and opportunities for different levels of transparency and existence of regulations and laws ${ }^{\mathrm{a}}$.

${ }^{\text {a }}$ See Table 2 for belief values. 
Srivastava, Rajendra. (2009) Bayesian and Belief Functions Formulas for Auditor Independence Risk Assessment. International

Journal of Auditing, 3, 163-183. Publisher's Official Version: <http://onlinelibrary.wiley.com/journal/10.1111/\%28ISSN\%291099-1123>. Open Access Version: <http://kuscholarworks.ku.edu/dspace/>.

\section{Independence risk: \\ Plausibility of impaired independence
Naïve observer: Plausibility of impaired independence as perceived by an observer having minimal information about the relationship between the independent auditor and the audit client or about the effectiveness of safeguards affecting that relationship. \\ Signaling: Plausibility of impaired independence perceived by an observer after increased signaling by independent auditor regarding nature of threats and the effectiveness of safeguards. \\ Regulation: Plausibility of impaired independence perceived by an observer after increased signaling by the profession and regulators regarding nature of threats and effectiveness of safeguards and after implementation of increased regulations and laws, such as Sarbanes-Oxley Act of 2002. \\ Auditor: Plausibility of impaired independence self-assessed by independent auditor.}

\section{Figure 4: Continued}

the lower panel shows the assessed independence risk based on Bayes theory for differing levels of knowledge concerning factors that influence independence risk. In this figure, we first plot the assessment of independence risk by a 'naïve observer' who has very limited knowledge of the nature of the profession, the policies and procedures of audit firms, and/or of the effectiveness of safeguards implemented by regulators.

Since we assume for a 'naïve observer' there is very limited knowledge that specific threats either do or do not exist, we set the belief values related to threats at relatively high levels, i.e., on a $0.0-1.0$ scale, we consider 0.7 level of belief that Incentives are present, 0.5 level of belief that Attitude is present, and 0.7 level of belief that Opportunities are present. We assume zero level of belief for the negation of Incentives, Attitude, and Opportunities.

The assumed values are shown in Table 2. In addition, we set the effectiveness of safeguards related to the auditor's Attitude at a relatively low level, say 0.2 , under the DS framework. We then vary the level of effectiveness of the safeguard related to Incentive and Opportunity, from 0 to 1.0 in increments of 0.1 . This circumstance is plotted as 'naïve observer' in Figure 4.

As can be seen, the naïve observer's perception of the risk of impaired independence is very high when there is no belief in the effectiveness in safeguards, but declines rapidly as this effectiveness increases and rapidly approaches zero with the perception of completely effective safeguards.

In contrast, the auditor's assessment of risk likely will result in much lower beliefs that threats exist and much higher beliefs that safeguards exist and are effective. As shown in Table 2, to reflect this view we set the belief values related to threats at relatively low levels, i.e., we consider 0.4 level of belief that Incentives are present, 0.2 level of belief that Attitude is present, and 0.4 level of belief that Opportunities are present. In addition, we set the assessment of the effectiveness of safeguards related to the auditor's Attitude at 0.9 , a relatively high level. As with the naïve observer, we then vary the level of effectiveness of Incentive and Opportunity safeguards from 0 to 1.0 in increments of 0.1 . This baseline is plotted as 'Auditor' for both frameworks, DS and Bayesian, in Figure 4. Of course, as previously noted, assessed belief values or probabilities may result either from unbiased or biased self-assessments.

Any difference between the plots of the "naïve observer' and the other plots provides an estimate of the value of transparency; that is, the value of communicating to naïve observers information about the effectiveness of both the audit firm's and the regulator's safeguards that are in place. Such a difference also represents a potential 'expectation gap' between the auditors self-assessment of independence and an assessment made by someone not fully cognizant of actual threats or effective safeguards that may exist. 
Srivastava, Rajendra. (2009) Bayesian and Belief Functions Formulas for Auditor Independence Risk Assessment. International Journal of Auditing, 3, 163-183. Publisher's Official Version: <http://onlinelibrary.wiley.com/journal/10.1111/\%28ISSN\%291099-1123>. Open Access Version: <http://kuscholarworks.ku.edu/dspace/>.

Table 2: Belief values for Figure 4 assuming a medium level of interrelationships among the three factors $\left(r_{1}=r_{2}=r_{3}=0.6\right.$ or $\left.\rho_{1}=\rho_{2}=\rho_{3}=0.714\right)$

\begin{tabular}{|c|c|c|}
\hline \multirow{2}{*}{$\begin{array}{l}\text { Factors for which evidence gathered } \\
\text { Threats related to Incentives in terms of } \\
\text { m-values in support of, against, and } \\
\text { ambiguity }\end{array}$} & \multicolumn{2}{|c|}{ Basic belief masses, i.e., m-values } \\
\hline & $\begin{array}{l}\text { Naïve observer: } \\
\text { Signaling: } \\
\text { Regulation: } \\
\text { Auditor: }\end{array}$ & $\begin{array}{l}\{0.7,0.0,0.3\} \\
\{0.6,0.0,0.4\} \\
\{0.5,0.0,0.5\} \\
\{0.4,0.0,0.6\}\end{array}$ \\
\hline $\begin{array}{l}\text { Effectiveness of safeguards related to } \\
\text { threats pertaining to Incentives }\end{array}$ & $\begin{array}{l}\text { Naïve observer: } \\
\text { Signaling: } \\
\text { Regulation: } \\
\text { Auditor: }\end{array}$ & $\begin{array}{l}\{*\} \\
* *\} \\
* *\} \\
* *\}\end{array}$ \\
\hline $\begin{array}{l}\text { Threats related to Attitude in terms of } \\
\text { m-values in support of, against, and } \\
\text { ambiguity }\end{array}$ & $\begin{array}{l}\text { Naïve observer: } \\
\text { Signaling: } \\
\text { Regulation: } \\
\text { Auditor: }\end{array}$ & $\begin{array}{l}\{0.5,0.0,0.5\} \\
\{0.4,0.0,0.6\} \\
\{0.3,0.0,0.7\} \\
\{0.2,0.0,0.8\}\end{array}$ \\
\hline $\begin{array}{l}\text { Effectiveness of safeguards related to } \\
\text { threats pertaining to Attitude }\end{array}$ & $\begin{array}{l}\text { Naïve observer: } \\
\text { Signaling: } \\
\text { Regulation: } \\
\text { Auditor: }\end{array}$ & $\begin{array}{l}\{0.2,0.0,0.8\} \\
\{0.4,0.0,0.6\} \\
\{0.6,0.0,0.4\} \\
\{0.9,0.0,0.1\}\end{array}$ \\
\hline $\begin{array}{l}\text { Threats related to Opportunities in terms } \\
\text { of m-values in support of, against, and } \\
\text { ambiguity }\end{array}$ & $\begin{array}{l}\text { Naïve observer: } \\
\text { Signaling: } \\
\text { Regulation: } \\
\text { Auditor: }\end{array}$ & $\begin{array}{l}\{0.7,0.0,0.3\} \\
\{0.6,0.0,0.4\} \\
\{0.5,0.0,0.5\} \\
\{0.4,0.0,0.6\}\end{array}$ \\
\hline $\begin{array}{l}\text { Effectiveness of safeguards related to } \\
\text { threats pertaining to Opportunities }\end{array}$ & $\begin{array}{l}\text { Naïve observer: } \\
\text { Signaling: } \\
\text { Regulation: } \\
\text { Auditor: }\end{array}$ & $\begin{array}{l}\{*\} \\
\{*\} \\
\{*\} \\
* *\}\end{array}$ \\
\hline
\end{tabular}

*Varied from 0.0 to 1.0 in increments of 0.1 .

Between plots for the naïve observer and for the auditor, we plot the effect on AIR of additional information communicated as the result of an audit firm providing greater transparency concerning audit firm-specific policies and procedures (plotted as 'Signaling' in Figure 4). Examples of this type of communication are provided in Houghton \& Trotman (2002, 2003), where KPMG Australia provides significant additional information concerning the methods it uses to help ensure auditor independence and by KPMG International in their KPMG's Transparency Report (KPMGI, 2005). As shown in Table 2, to reflect this circumstance we set the belief values related to threats at lower levels than that for the naïve observer, i.e., on a $0-1.0$ scale, we consider 0.6 level of belief that Incentives are present, 0.4 level of belief that Attitude is present, and 0.6 level of belief that Opportunities are present. In addition, we set the effectiveness of safeguards related to the auditor's Attitude at a higher level, 0.4, than for the naïve observer. As before, we then vary the level of effectiveness of Incentive and Opportunity safeguards from 0 to 1.0 in increments of 0.1 .
These three plots demonstrate the value of formal models in assessing independence risk and more specifically the usefulness of signaling as a means of reducing existing information asymmetry between external observers and individual audit firms. Such signaling may provide some comfort to external observers in regard to how an audit firm controls independence risk, thereby reducing the belief that threats exist and increasing belief that effective safeguards are in place.

\section{The perceived effect of additional regulation}

Our model may also be utilized to assess the effects on independence risk of changes or differences in the regulatory environment. For example, because of specific restrictions contained in SOX and the degree of publicity accorded the act, even naïve observers may perceive that some threats, such as providing lucrative non-audit services to clients, have been eliminated and that effective safeguards such as audit partner rotation will mitigate other threats. As a result, increased knowledge of threat reductions and safeguard implementations 
Srivastava, Rajendra. (2009) Bayesian and Belief Functions Formulas for Auditor Independence Risk Assessment. International Journal of Auditing, 3, 163-183. Publisher's Official Version: <http://onlinelibrary.wiley.com/journal/10.1111/\%28ISSN\%291099-1123>. Open Access Version: <http://kuscholarworks.ku.edu/dspace/>.

required by regulation can substantially reduce the plausibility and probability of impaired independence as viewed by a naïve observer.

Figure 4 plots an assessment of independence risk under both frameworks given that the auditor actively signals regarding threats and the effectiveness of safeguards to external observers and that increased regulations and laws, such as SOX, are implemented and publicized to external observers (plotted as 'Regulation' in Figure 4). To reflect this circumstance, we set the belief values related to threats at lower levels than that for the naïve observer with signaling by audit firms, i.e., on a $0-1$ scale, we consider a 0.5 level of belief that Incentives are present, a 0.3 level of belief that Attitude is present, and a 0.5 level of belief that Opportunities are present. In addition, we set the effectiveness of safeguards related to the auditor's Attitude at a higher level, 0.6, than for the naïve observer with signaling. These values are shown in Table 2. As before, we then vary the level of the effectiveness of Incentive and Opportunity safeguards from 0 to 1.0 in increments of 0.1 .

Although we illustrate possible differences in Figure 4 based on our estimate as to what relative degree various influences may have on perceptions of the risk of impaired independence, measurement of actual changes in beliefs is an empirical question. Future research should focus on the sensitivity of beliefs to such influences as signaling by audit firms and promulgation of strict regulations and laws by governing bodies.

While the above discussion presents the impact of additional regulation on independence risk, it is also important to recognize that perceptions of the interrelationships and the Opportunity set may be time dependent, i.e., they may change with time and experience. For example, prior to the failed audits of Enron by Arthur Andersen, regulators, lawmakers, and other stakeholders may have implicitly believed that interrelationships among the three factors were not especially strong. Once the failed audits became known, however, regulators and lawmakers may have implicitly perceived stronger relationships among these factors.

Also, a stronger perception may have emerged that auditors might be more likely to take advantage of an Opportunity than previously believed, i.e., there was an increased belief in an inappropriate auditor Attitude. As a result, perceived independence risk likely increased dramatically with increased values for the interrelationships and for higher values of the belief in Attitude. It is possible that the US Congress had similar perceptions about independence risk and, when combined with political pressures, passed the Sarbanes-Oxley Act of 2002. This new law is partially intended to control independence risk by creating and enforcing new and stronger safeguards. These stronger safeguards may lead to lower independence risk with a potential result shown in Figure 4.

\section{CONCLUSION}

In this paper we present and illustrate two analytical formulas for evaluation of risk of impaired auditor independence. The presentation of formulas based on both Bayesian Theory (BT) and the theory of belief functions (BF) provides alternatives to assess independence risk depending on factors such as the feasibility of obtaining the parameters needed to implement each approach and the complexity of each formula. This paper extends Turner et al. (2002) by taking a threats-safeguards approach such as that included in the international auditing standards and by providing two analytical formulas for independence risk for both negative and positive evidence situations (i.e., evidence concerning both threats and effective safeguards).

Independence risk is presented as a function of six risk factors. Three of these risks relate to the existence of threats to auditor independence: risk that the auditor has Incentive to be biased in favor of an audit client; risk that the auditor has an inappropriate Attitude that may lead to such bias; and risk that there are Opportunities for the auditor to exhibit bias in providing the audit opinion. The second three relate to the risk that effective safeguards do not exist to control each of the corresponding three risks arising from threats. For the first time, interrelationships between the factors that influence auditor independence risk are also modeled and analyzed.

To provide additional insights into the usefulness of analytical modeling, we assess independence risk from two important viewpoints. The first demonstrates the existence of a possible 'expectation gap' between external risk assessments made by a 'naïve' observer, not having access to all relevant information, and internal risk assessments made by the auditor. In making an internal assessment, the auditor has access to more 
information about threats and the effectiveness of safeguards, but the assessment may be biased in favor of the auditor. The substantial disparity shown in Figure 4 between assessments by the two parties indicates the potential value of signaling of independence by auditors through greater disclosure of how auditor independence is maintained. KPMG Australia has attempted to signal its level of independence with reviews performed by Houghton \& Trotman $(2002,2003)$. KPMG International also has published a report (KPMGI, 2005) which describes how the firm monitors compliance with its policies and procedures regarding independence and describes the KPMG Independence Compliance System (KICS) that facilitates monitoring of partner, manager, and firm reportable investments. As illustrated in this paper, the use of an analytical model facilitates the quantification of the reduction in the overall level of perceived independence risk as the policies and procedures used to limit independence risk become more transparent.

The second viewpoint demonstrates how knowledge of additional effective external safeguards, such as those resulting from changes in regulations, may affect external observer assessments. Figure 4 shows that implementation of stringent regulations by governing bodies may greatly impact the assessment of independence risk.

While our examples demonstrate the potential usefulness of our models for assessing the risk of impaired independence, a number of questions requiring empirical research remain. First, given that auditors may not be considered totally independent from their clients because of financial ties through audit fees, one area requiring research is to investigate the level of independence risk acceptable both to regulators and to financial statement users. Second, the Bayesian formula presented here needs empirical research to assess the probability potentials, conditional probabilities and other probabilities included in the formula. Similarly, the belief function formula requires empirical research investigating how evidence of threats and safeguards and the interrelationships between those factors should be measured and weighted. Third, both formulas imply that greater disclosure by auditors can reduce the information asymmetry between auditors and external observers. This in turn, can reduce the appearance of impaired independence. The nature and degree of additional disclosures regarding audit program decisions, materiality choice, and other issues provide a fertile area for empirical academic research. Finally, future research is needed to help determine which approach, i.e., Bayesian or belief functions, actually is more useful in practice. Until these questions are addressed, recommendations such as policy changes would be premature.

\section{ACKNOWLEDGEMENTS}

Helpful suggestions for this paper have been received at workshops at the University of Muenster, Victoria University of Technology, and Sydney University and from Gary Monroe, Colleen Hayes, Christiane Strohm and Reiner Quick. Support for this research has been provided by the Universities of Southern California, Kansas, and Memphis and by The Australia National University.

\section{NOTES}

1. This relationship could also be expressed as 'OR' if we consider the negations of the variables, which is expressed in mathematical terms as: $\sim \mathrm{b}=\sim \mathrm{i} \vee \sim \mathrm{a} \vee \sim \mathrm{o}$, where the symbol $\vee$ represents the union relationship.

2. Srivastava \& Mock (2005) provide additional justification as to why belief functions provide a useful framework for these kinds of issues.

3. Here there are three likelihood ratios, $\lambda_{\mathrm{I}}, \lambda_{\mathrm{A}}$, and $\lambda_{\mathrm{O}}$, for factors I, A, and $\mathrm{O}$, respectively. These likelihood ratios are defined in terms of conditional probabilities. For example, $\lambda_{\mathrm{I}}=\mathrm{P}\left(\mathrm{E}_{\mathrm{TI}} \mathrm{E}_{\mathrm{SI}} \mid \mathrm{i}\right) / \mathrm{P}\left(\mathrm{E}_{\mathrm{TI}} \mathrm{E}_{\mathrm{SI}} \mid \sim \mathrm{i}\right)$, where $\mathrm{E}_{\mathrm{TI}} \mathrm{E}_{\mathrm{SI}}$ jointly represent the evidence from threats and safeguards pertaining to the variable I. Other likelihood ratios are defined in similar ways.

4. $\mathrm{m}^{+}$represents the basic belief mass, i.e., $\mathrm{m}$-value, in support of the variable denoted by its subscript, $\mathrm{m}^{-}$represents the basic belief mass, i.e., $m$-value, against the variable denoted by its subscript, and $\mathrm{m}^{\Theta}$ represents the basic belief mass, i.e., m-value, representing unassigned belief. The sum of all the $\mathrm{m}$-values assessed from an item of evidence is always 1 .

5. Cobb \& Shenoy (2003) have proposed a theoretically sound approach to convert $\mathrm{m}$-values in DS theory to probabilities in Bayesian framework. In their approach the normalized plausibility for each state of nature represents the probability of the each state of nature. For example, consider the following 
Srivastava, Rajendra. (2009) Bayesian and Belief Functions Formulas for Auditor Independence Risk Assessment. International Journal of Auditing, 3, 163-183. Publisher's Official Version: <http://onlinelibrary.wiley.com/journal/10.1111/\%28ISSN\%291099-1123>. Open Access Version: <http://kuscholarworks.ku.edu/dspace/>.

inputs of belief masses for a binary variable $X$ : $\mathrm{m}(\mathrm{x})=0.7, \mathrm{~m}(\sim \mathrm{x})=0.1, \mathrm{~m}(\{\mathrm{x}, \sim \mathrm{x}\})=0.2$. For these values, we have the following plausibilities: $\mathrm{Pl}(\mathrm{x})=0.9$, and $\mathrm{Pl}(\sim \mathrm{x})=0.3$. When normalized they yield the following probabilities: $\mathrm{P}(\mathrm{x})=0.9 / 1.2$, and $\mathrm{P}(\sim \mathrm{x})=0.3 / 1.2$. We use this approach to convert all $\mathrm{m}$-values in DS theory to probabilities and then to likelihood ratios and strengths of relationships in Bayesian theory. There is no transformation available for converting probabilities to belief masses.

\section{REFERENCES}

American Institute of Certified Public Accountants (AICPA) (1972), Codification of Auditing Standards and Procedures. Statement on Auditing Standards No. 1. New York: AICPA.

American Institute of Certified Public Accountants (AICPA) (2002), Consideration of Fraud in a Financial Statement Audit. Statement on Auditing Standards No. 99. New York: AICPA

American Institute of Certified Public Accountants (AICPA) (2005), AICPA Plain English Guide to Independence, March 1, 2005. New York: AICPA. Available at http://www.aicpa.org/download/ ethics/plainenglish.doc.

Antle, R., Griffin, P., Teece, D. \& Williamson, O. (1997), An Economic Analysis of Auditor Independence for a Multiclient, Multi-Service Public Accounting Firm. Prepared on behalf of the AICPA in Connection with the Presentation to the Independence Standards Board of 'Serving the Public Interest: A New Conceptual Framework for Auditor Independence'. Available at http:// www.aicpa.org/members/div/secps/isb/white. htm.

Ashbaugh H., LaFond, R. \& Mayhew, B. W. (2003), 'Do nonaudit services compromise auditor independence? Further evidence', The Accounting Review, Vol. 78, No. 3, pp. 611-39.

Bloom, R. \& Myring, M. (2002), 'GAO's 2002 new auditor independence rules', The Journal of Government Financial Management, Vol. 51, No. 3, pp. 44-9.

Brandon, D., Crabtree, A. \& Maher, J. (2004), 'Nonaudit fees, auditor independence, and bond ratings', Auditing: A Journal of Practice and Theory, Vol. 23, No. 2, pp. 89-103.

Burke, W. (1997), Auditor Independence: An Organizational Psychology Perspective. A Report Prepared on behalf of the AICPA for Presentation to the Independence Standards Board of 'Serving the Public Interest: A New Conceptual Framework for Auditor Independence'. Available at http:// www.aicpa.org/members/div/secps/isb/white. htm.

Chen, S. Y., Lin, W. C. \& Chen, C. T. (1992), 'Spatial reasoning based on multivariate belief functions',
Proceedings of 1992 IEEE Computer Society Conference on Computer Vision and Pattern Recognition, Champaign, IL, June, pp. 624-6.

Chung, H. \& Kallapur, S. (2003), 'Client importance, nonaudit services, and abnormal accruals', The Accounting Review, Vol. 78, No. 4, pp. 931-55.

Cobb, B. \& Shenoy, P. (2003), 'A comparison of Bayesian and belief function reasoning', Information Systems Frontiers, Vol. 5, No. 4, pp. $345-58$.

DeFond, M. L., Raghunandan, K. \& Subramanyam, K. R. (2002), 'Do non-audit service fees impair auditor independence? Evidence from going concern audit opinions', Journal of Accounting Research, Vol. 40, No. 4, pp. 1247-74.

Démotier, S., Schön, W. \& Denoeux, T. (2003), ‘Risk assessment based on weak information using belief functions: A case study in water treatment', IEEE Transactions on Systems, Man and Cybernetics - Part C: Applications and Reviews, Vol. 2, October, pp. $1792-7$.

Edwards, A. W. F. (1984), Likelihood: An Account of the Statistical Concept of Likelihood and its Application to Scientific Inferences. Cambridge: Cambridge University Press,

Frankel, R. M., Johnson, M. F. \& Nelson, K. K. (2002), 'The relation between auditors' fees for nonaudit services and earnings quality', The Accounting Review, Vol. 77, Supplement, pp. 71-114.

Glazer, A. \& Jaenicke, H. (2002), 'A pathology of the Independence Standards Board's Conceptual Framework Project', Accounting Horizons, Vol. 16, No. 4, pp. 329-52.

Hodge, F. (2003), 'Investor's perceptions of earnings quality, auditor independence, and the usefulness of audited financial information', Accounting Horizons, Vol. 17, Supplement, pp. 37-48.

Houghton, K. \& Trotman, K. (2002), Review of KPMG Australia's Processes and Policies in Respect of Independence, Conflict Resolution and Quality Controls, Sydney: KPMG Australia.

Houghton, K. \& Trotman, K. (2003), Review of KPMG Australia's Processes and Policies in Respect of Independence, Conflict Resolution and Quality Controls, Sydney: KPMG Australia.

Independence Standards Board (ISB) (2000), 'Statement of Independence Concepts: A Conceptual Framework for Auditor Independence', Exposure Draft. New York: Independence Standards Board.

International Federation of Accountants (IFAC) (2008), Handbook of International Auditing, Assurance, and Ethics Pronouncements 2008 Edition. New York: IFAC.

Jaffray, J-Y. (1989), 'Utility theory for belief functions', Operations Research Letters, Vol. 8, pp. 107-12.

Jaffray, J-Y. (1994), 'Dynamic decision making with belief functions', in Yager, R. R., Fedrizzi, M. \& Kacprzyk, J. (eds), Advances in the Dempster-Shafer Theory of Evidence. New York: John Wiley \& Sons. 
Srivastava, Rajendra. (2009) Bayesian and Belief Functions Formulas for Auditor Independence Risk Assessment. International Journal of Auditing, 3, 163-183. Publisher's Official Version: <http://onlinelibrary.wiley.com/journal/10.1111/\%28ISSN\%291099-1123>. Open Access Version: <http://kuscholarworks.ku.edu/dspace/>.

Jenkins, J. G. \& Krawczyk, K. (2002), 'The relationship between nonaudit services and perceived auditor independence', Journal of Business and Economic Perspectives, Fall/Winter, pp. 25-36.

Johnstone, K., Sutton, M. \& Warfield, T. (2001), 'Antecedents and consequences of independence risk: Framework for analysis', Accounting Horizons, Vol. 15, No. 1, pp. 1-18.

Kohlberg, L. (1971), 'From is to ought: How to commit the naturalistic fallacy and get away with it in the study of moral development', in Mischel, T. (ed.), Cognitive Development and Epistemology. New York: Academic Press, pp. 151-235.

KPMG International (KPMGI) (2005), KPMG's Transparency Report. Publication number 212-025. Available at http://www.kpmg.com/ NR/rdonlyres / A75F1CFF-AAB7-4D69-A489690396C9094A/0/KPMGIntlTransparencyReport. pdf.

Maleszka, T. \& Monroe, G. (2004), ‘Perceptions of auditor independence', Working paper, Australian National University.

McBurney, P. \& Parsons, S. (2002), 'Using belief functions to forecast demand for mobile satellite services', in Srivastava, R. P. \& Mock, T. (eds), Belief Functions in Business Decisions. Heidelberg: Springer-Verlag, pp. 281-315.

Nguyen, H. T. \& Walker, E. A. (1994), 'On decision making using belief functions', in Yager, R. R., Fedrizzi, M. \& Kacprzyk, J. (eds), Advances in the Dempster-Shafer Theory of Evidence. New York: John Wiley \& Sons.

Office of the Chief Accountant (OCA) (2007), 'Audit Committees and Auditor Independence'. Washington, DC: Securities and Exchange Commission. Available at http://www.sec.gov/ info/accountants/audit042707.htm.

Ponemon, L. (1990), 'Ethical judgments in accounting: A cognitive developmental perspective', Critical Perspectives in Accounting, Vol. 1, pp. 191-215.

Ponemon, L. (1992), 'Auditor underreporting of time and moral reasoning: An experimental lab study', Contemporary Accounting Research, Vol. 9, pp. $171-89$.

Ponemon, L. (1993), 'The influence of ethical reasoning on auditors' perceptions of management's competence and integrity', Advances in Accounting, Vol. 11, pp. 1-29.

Ponemon, L. (1995), 'The objectivity of accountants' litigation support judgments', The Accounting Review, Vol. 70, No. 3, pp. 467-88.

Rest, J. (1986a), Moral Development: Advances in Theory and Practice. New York: Praeger.

Rest, J. (1986b), DIT Manual. Minneapolis, MN: Center for the Study of Ethical Development.

Reynolds, K., Deis, D. \& Francis, J. (2004), 'Professional service fees and auditor objectivity', Auditing: A Journal of Practice \& Theory, Vol. 23, No. 1, pp. 29-52.

Ryan, S., Herz, R., Iannaconi, T., Maines, L., Palepu, K., Schrand, C., Skinner, D. \& Vincent, L. (2001), 'SEC auditor independence requirements', Accounting Horizons, Vol. 15, No. 4, pp. 373-86.

Securities and Exchange Commission (SEC) (2000), Testimony of Ralph Whitworth, Managing Member, Relational Investors LLC (13 September).

Securities and Exchange Commission (SEC) (2001), Final Rule: Revision of the Commission's Auditor Independence Requirements, Securities and Exchange Commission 17 CFR Parts 210 and 240. February 5.

Shafer, G. (1976), A Mathematical Theory of Evidence. Princeton, NJ: Princeton University Press.

Shafer, G. \& Tversky, A. (1985), 'Languages and designs for probability judgment', Cognitive Science, Vol. 9, pp. 309-39.

Shafer, W., Morris, R. \& Ketchand, A. (1999), 'The effects of formal sanctions on auditor independence', Auditing: A Journal of Practice and Theory, Vol. 18, No. 2, Supplement, pp. 85-101.

Shaub, M. (1994), 'An analysis of the association of traditional demographic variables with the moral reasoning of auditing students and auditors', Journal of Accounting Education, Vol. 12, pp. 126.

Shenoy, P. \& Shafer, G. (1990), 'Axioms for probability and belief-function computation', in Shachter, R. D., Levitt, T. S., Lemmer, J. F. \& Kanal, L. N. (eds), Uncertainty in Artificial Intelligence, Vol. 4, Amsterdam: North-Holland, pp. 169-98.

Srivastava, R. \& Mock, T. (2000), 'Evidential reasoning for WebTrust assurance services', Journal of Management Information Systems, Vol. 16, No. 3, pp. 11-32.

Srivastava, R. \& Mock, T. (2005), 'Why we should consider belief functions in auditing research and practice', The Auditor's Report, Vol. 28, No. 2.

Srivastava, R. \& Shafer, G. (1992), 'Belief-function formulas for audit risk', The Accounting Review, Vol. 67, No. 2, pp. 249-83.

Srivastava, R., Mock, T. \& Turner, J. (2007), 'Analytical formulas for risk assessment for a class of problems where risk depends on three interrelated variables', International Journal of Approximate Reasoning, Vol. 45 , No. 1, pp. 123-51.

Srivastava, R., Mock, T. \& Turner, J. (2009), 'A fraud risk formula for financial statement audits under the Bayesian framework', Abacus, Vol. 45, No. 1, pp. 66-87.

Sun, L., Srivastava, R. \& Mock, T. (2006), 'An information systems security risk assessment model under Dempster-Shafer theory of belief functions', Journal of Management Information Systems, Vol. 22, No. 4, pp. 109-42.

Taylor, M., DeZoort, T., Munn, E. \& Thomas, M. (2003), 'A proposed framework emphasizing auditor reliability over auditor independence', Accounting Horizons, Vol. 17, No. 3, pp. 257-66.

Tsui, J. \& Gul, F. (1995), 'Auditors' behavior in an audit conflict situation: A research note on the role of locus of control and ethical reasoning', Accounting, Organizations and Society, Vol. 21, pp. 41-51. 
Srivastava, Rajendra. (2009) Bayesian and Belief Functions Formulas for Auditor Independence Risk Assessment. International Journal of Auditing, 3, 163-183. Publisher's Official Version: <http://onlinelibrary.wiley.com/journal/10.1111/\%28ISSN\%291099-1123>. Open Access Version: <http://kuscholarworks.ku.edu/dspace/>.

Turner, J., Mock, T. \& Srivastava, R. (2002), 'A formal model of auditor independence risk', Australian Accounting Review, Vol. 12, No. 2, pp. 31-8.

Yager, R. R. (1990), 'Decision making Under Dempster-Shafer Uncertainties', Technical Report MII-915. New Rochelle, NY: Iona College.

\section{AUTHOR PROFILES}

Rajendra P. Srivastava is Ernst \& Young Distinguished Professor of Accounting and Director of the Ernst \& Young Center for Auditing Research and Advanced Technology at the School of Business, University of Kansas. He holds a PhD in Accounting from the University of Oklahoma, Norman (1982) and a PhD in Physics from Oregon State University, Corvallis (1972). Professor Srivastava has published over 80 papers in refereed journals. His publications have appeared in The Accounting Review, Journal of Accounting Research, Auditing: A Journal of Practice and Theory, Journal of Management Information Systems, Journal of Information Systems, Decision Support Systems, and many other accounting and AI journals.

He received the 1996 Award for Notable Contribution to AI \& Expert Systems Research in Accounting from the AI/Emerging Technology Section of the American Accounting Association. $\mathrm{He}$ is currently Associate Editor of Journal of Emerging Technologies in Accounting, AI/ET Section Journal of the American Accounting Association, and has been a member of the Editorial and Review Board of several journals including The Accounting Review (1989-93), Auditing: A Journal of Practice $\mathcal{E}$ Theory (July 1993-2005, 2008-present), Indian Accounting Review, International Journal of Auditing, and International Journal of Accounting and Information Systems. Professor Srivastava served as the Chairman of the AI/Emerging Technology Section of American Accounting Association during 1994-95.

Theodore J. (Ted) Mock is Distinguished Professor of Auditing and Assurance at the
University of California, Riverside and Professor of Auditing Research at Maastricht University in the Netherlands. From 1982 to 2006 he served as Arthur Andersen Alumni Professor at the University of Southern California (USC). In 1983 he helped found the USC Audit Judgment Symposium (now the International Symposium on Audit Research).

Ted's research interests lie primarily in the areas of audit judgment, assurance services, evidential reasoning and sustainability. His AICPA research monograph with J. L. Turner on internal control evaluation was awarded the American Accounting Association Wildman Award. In 2003 he received the AAA Auditing Section Outstanding Auditing Educator award and in 2006 the AAA ABO Notable [Lifetime] Contribution Award. His research has appeared in many journals including Auditing: $A$ Journal of Practice $\mathcal{E}$ Theory, The Accounting Review, the Journal of Accounting Research, Accounting, Organizations and Society, the Journal of Management Information Systems, the Journal of Information Systems, and Decision Support Systems.

Professor Mock's training includes degrees in mathematics and finance from The Ohio State University and a doctorate from The University of California, Berkeley. Ted has served many positions within the American Accounting Association including editor of Auditing: A Journal of Practice $\mathcal{E}$ Theory, Director of Research, and President of the Auditing Section.

Jerry L. Turner is a Professor of Accountancy at The University of Memphis in Memphis, Tennessee. His primary teaching and research interests are in auditing and accounting information systems. In addition to two research monographs, he has published in the Journal of Accounting, Auditing and Finance, Abacus, the International Journal of Auditing, the Journal of Forensic Accounting, the International Journal of Approximate Reasoning, Current Issues in Auditing, and other journals. 